\title{
ЯВЛЯЕТСЯ ЛИ ИНТЕРНЕТ СБЕРЕГАЮЩИМ ЗДОРОВЬЕ ФАКТОРОМ В РОССИИ?
}

\author{
ИРИНА КАЛАБИХИНА, АНТОН КОЛОТУША
}

\begin{abstract}
В связи с растущей популярностью сети Интернет в России представляется важным выяснить, как частота его использования сказывается на состоянии здоровья людей и самосохранительном поведении. В настоящей работе мы тестируем оптимистичные гипотезы, согласно которым, при прочих равных условиях, относительно частое использование Интернета соответствует лучшему состоянию здоровья и меньшему потреблению алкогольной и табачной продукции. Опираясь на данные последних трех волн (2014, 2016, 2018 г.) Комплексного обследования условий жизни населения (КОУЖ), мы строим модели бинарного пробита с использованием инструментальных переменных для определения влияния Интернета на здоровье и тобит-модели в первых разностях для оченки его влияния на объёмы потребления алкогольной и табачной продукции. Первая группа моделей демонстрирует значимое положительное влияние Интернета на состояние здоровья для обоих полов. В остальных моделях гипотезы анализа подтверждаются частично: с повышением частоты пользования Интернетом мужчины меньше курят и пьют, больше предпочитают слабоалкогольные напитки, но на женской выборке результат не подтверждает гипотезу позитивного влияния Интернета на снижение потребления табака и алкоголя. Мы полагаем, что объяснение такого результата лежит в области качества данных, а также стадии эмансипации женщин в России. Кроме того, Интернет не является для женщин заменителем «водочного» досуга в отличие от мужчин.
\end{abstract}

Исходя из вышеизложенного, мы можем сформулировать общий вывод, что для сохранения и укрепления здоровья жителей России следует расширять возможности использования Интернета.

Ключевые слова: Интернет, здоровье, самосохранительное поведение, тобит-модели, бинарные пробит-модели, алкоголь, курение.

\section{ОБЗОР ЛИТЕРАТУРЫ И ИССЛЕДОВАТЕЛЬСКИЕ ГИПОТЕЗЫ}

С развитием интернет-технологий в зарубежной литературе появились первые работы, в которых были выдвинуты предположения о будущих экономических, социологических и демографических последствиях цифровизации (DiMaggio et al. 2001; Kling 2000; Cesare et al. 2018; Калабихина 2019). Замечено, что демографические последствия цифровизации комплексные (затрагивает все процессы) и разнонаправленные (могут иметь положительный и отрицательный характер) (Калабихина 2019).

\footnotetext{
ИРИНА ЕВГЕНЬЕВНА КАЛАБИХИНА (ikalabikhina@yandex.ru), МОСКОВСКИЙ ГОСУДАРСТВЕННЫЙ УНИВЕРСИТЕТ ИМЕНИ М.В. ЛОМОНОСОВА, РосСИЯ.

АНТОН ВАСИЛЬЕВИч КОЛОТУША (tony_kol@mail.ru), МОСКОВСКИЙ ГОСУДАРСТВЕННЫЙ УНИВЕРСИТЕТ ИМЕНИ М.В. ЛомОносовА, Россия.

РУКОПИСЬ ПОДГОТОВЛЕНА ПРИ ФИНАНСОВОЙ ПОДДЕРЖКЕ ЭКОНОМИЧЕСКОГО ФАКУЛЬТЕТА МОСКОВСКОГО ГОСУДАРСТВЕННОГО УНИВЕРСИТЕТА ИМЕНИ М.В. ЛОМОНОСОВА В РАМКАХ НАУЧНО-ИССЛЕДОВАТЕЛЬСКОЙ РАБОТЫ НА ТЕМУ «ВОСПРОИЗВОДСТВО НАСЕЛЕНИЯ В ЦИФРОВОМ ОБЩЕСТВЕ».
}

СТАТЬЯ ПОСТУПИЛА В РЕДАКЦИЮ в ИЮНЕ 2020 Г. 
На данный момент нет однозначных доказательств позитивного или негативного влияния Интернета на здоровье. Например, в работе (Груздева 2017) подмечается, что Интернет, с одной стороны, может побуждать индивидов вести здоровый образ жизни, а с другой - пропагандировать нездоровый. Помимо полезной информации о применении самосохранительных практик блогосфера может служить источником ложной и непроверенной информации.

Приведем примеры положительного и отрицательного влияния Интернета на здоровье (речь идет о доступе к высокоскоростному ${ }^{1}$ Интернету), которое проявляется в изменении самосохранительного поведения, собственно уровня здоровья и уровня самооценки здоровья (таблица 1).

\section{Таблица 1. Потенциальное влияние доступа к Интернету на здоровье}

\begin{tabular}{l}
$\begin{array}{c}\text { Направления воздействия доступа к } \\
\text { Интернету на здоровье }\end{array}$ \\
\hline \multicolumn{1}{c}{ П) Улучш } \\
Снижение потребления табака и \\
алкоголя \\
Замещение потребления тяжелого \\
алкоголя более легким \\
Ведение здорового образа жизни не \\
только в отношении отказа от вредных \\
привычек (здоровое питание, занятие \\
физкультурой, здоровый сон и др.) \\
Более частое и своевременное \\
посещение врача
\end{tabular}

Использование современных средств контрацепции и забота о репродуктивном здоровье

Снижение заболеваемости (и смертности) от различных причин

Экономия времени и сил, сбережение здоровья

Рост уровня жизни, уровня занятости и предпринимательской активности
Способы воздействия доступа к Интернету на здоровье

Примеры положительного влияния

Просвещение о вреде курения и потребления алкоголя (Killian 2012)

Замещение вредных привычек другими видами досуга Распространение модных инноваций (например, здоровый образ жизни)

Распространение услуг для ведения здорового образа жизни (Feil et al. 2003; Swartz et al. 2006)

Повышение доступности медицинских услуг: рост доверия и навыков использования телемедицины внедрение технологических и организационных инноваций (дистанционная запись к врачу, заказ лекарств, получение дистанционных советов по профилактике и лечению заболеваний, получение второго диагноза, других услуг телемедицины)

Просвещение

Онлайн-консультации

Распространение медицинских и фармакологических товаров и услуг

2) Улучшение состояния здоровья

Повышение доступности медицинских услуг:

рост доверия и навыков использования телемедицины внедрение технологических и организационных инноваций (дистанционная запись к врачу, заказ лекарств, получение дистанционных советов по профилактике и лечению заболеваний, получение второго диагноза, других услуг телемедицины)

Повышение доступа к немедицинским дистанционным услугам (поиск и доставка товаров и услуг, финансовые операции)

Повышение доступа к дистанционной занятости (сокращается время на дорогу на работу, появляется гибкость в распределении времени и др.)

Повышение доступа к дистанционной занятости

\footnotetext{
${ }^{1}$ Широкополосный или высокоскоростной - Интернет, отличающийся как высокой одинаковой в обе стороны скоростью обмена данными (во много раз выше 56 кбит/с), так и непрерывным подключением без необходимости использования коммутатора (Вишневский и др. 2005).
} 


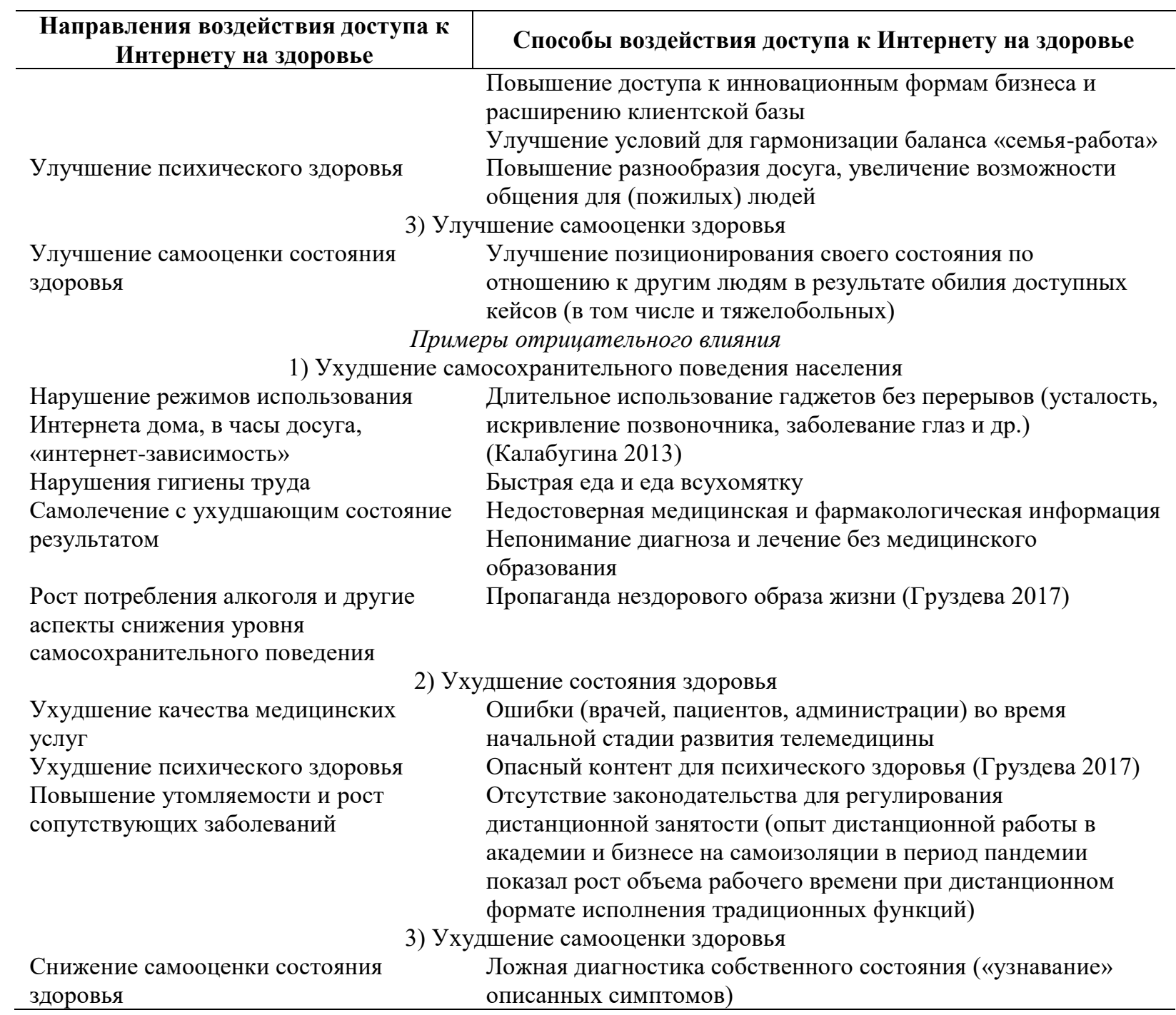

Источник: Разработано авторами.

Одним из важнейших аспектов влияния цифровизации на демографию является самосохранительное поведение. Вслед за отечественными исследователями-классиками А.И. Антоновым, В.А. Борисовым, В.М. Медковым в дискурс прочно вошло толкование самосохранительного поведения как системы действий и установок личности, направленных на сохранение здоровья в течение полного жизненного цикла, а также на продление срока жизни в пределах этого цикла (Антонов 1989; Борисов 1999; Медков 2002; Ревякин 2006).

Итоговый эффект влияния сети Интернет на самосохранительное поведение сильно зависит от личной ответственности пользователя и его способности осуществлять критическую оценку информации (Груздева 2017).

Если индивид изначально заинтересован в заботе о здоровье, то влияние Интернета на изменение его состояния здоровья также выглядит неопределённым: с одной стороны, он может упрощать возможности получения информации о профилактике и лечении, с другой, - он может быть источником недостоверных сведений и подталкивать индивида к пагубному самолечению. Кроме того, сокращению капитала здоровья может способствовать не только информация и характер побудительных установок, извлекаемых 
из Интернета, но и продолжительность работы с использованием электронных средств. Так, например, в работе Е. Калабугиной (2013) на основе статистических данных выборочного обследования студентов Южно-Уральского Государственного Университета (ЮУрГУ) установлено, что, в результате непрерывного пользования электронными средствами, около $70 \%$ респондентов отмечали усталость в глазах, а более $28 \%$ - усталость в позвоночнике при том, что продолжительность сессии составляет не менее 2 часов у чуть более $80 \%$ опрошенных студентов, а достаточно регулярно устраивают перерывы только $10 \%$ из них. При этом почти у каждого второго опрошенного отмечаются проблемы со зрением, а чуть менее, чем у $43 \%$ респондентов, - заболевания позвоночника.

Среди мотивов пользователей Интернета явно выражены мотивы аффилиации (потребности в принадлежности к определенной группе, что предполагает принятие её ценностей и следование им), а также мотивы общения и самоутверждения (Жеребин и др. 2017). Это даёт нам основание полагать, что влияние Интернета на самосохранительное поведение может носить устойчивый во времени характер.

Важно учитывать структуру спроса на медицинскую информацию: на основе бинарных логит-моделей выявлено, что люди уже больные (особенно хроническими заболеваниями), предъявляют спрос на информацию, связанную с возможностями лечения, в большей мере, нежели потенциальные больные (Bundorf et al. 2006). На основе рэндомизированных экспериментов (Feil et al. 2003; Swartz et al. 2006) и при построении мультиномиальных логит-моделей по данным опросов (Killian 2012) обнаружено позитивное краткосрочное влияние пропаганды здорового образа жизни на сокращение объёмов курения. Тем не менее заслуживает внимания то обстоятельство, что, как показывают бинарные логит-модели, некоторые психологические параметры (в частности, поиск новизны (novelty seeking)) у молодёжи могут быть одновременно источником как интернет-зависимости, так и курительных и алкогольных аддикций (June et al. 2007), а это может порождать эндогенность в исследованиях влияния распространения Интернета на подверженность курению из-за неучтённых факторов. Это подводит нас к мысли о важности учёта в моделях возрастного фактора, поскольку между разными возрастными группами могут наблюдаться различия в психическом состоянии, подталкивающем к подверженности различным зависимостям.

Важно также отметить, что анализировать оценку здоровья и самосохранительное поведение важно отдельно по полу, поскольку женщины и мужчины по-разному оценивают свое здоровье (Oskuzyan et al. 2008), а также имеют различное самосохранительное поведение (Демьянова 2005; Grøetvedt, Stavem, 2005; Bauer, Göhlmann, Sinning 2007). На примере потребления табака в России хорошо видны гендерные отличия (Калабихина, Кузнецова 2019): если мужчины прошли свой пик в уровне потребления табака, и в настоящее время мы видим снижение частоты потребления, то женщины «застряли»на высокой стадии потребления табака (хотя женщины продолжают уступать мужчинам в объемах потребления табака). Ссылаясь на теорию табачного перехода, изложенного в работах (Lopez, Collishaw, Piha 1994; Thun et al. 2012), авторы (Калабихина, Кузнецова 2019) отмечают различия в стадиях жизненного цикла курения у мужчин и женщин. Если для мужчин можно выделить две базовые фазы изменения отношения к курению: фазу подъёма (период, в котором курение ассоциируется с социальным успехом), сменяющуюся фазой 
спада (период, в котором с социальным успехом начинает ассоциироваться следование здоровому образу жизни), то у женщин на представленный выше двухфазный цикл накладывается процесс распространения эгалитарных установок в обществе. Таким образом, для женщин цикл становится трёхфазным: 1) низкий объём курения (вследствие осуждения такой модели поведения у женщин); 2) рост объёмов курения (связанный с постепенных снятием моральных ограничений на курение у женщин); 3) снижение объёмов курения (связанное с преобладанием моды на здоровый образ жизни).

Теория табачного перехода использует теорию диффузии инноваций, рассматривая в качестве инновации и рост потребления табака, и рост интереса к здоровому образу жизни. Важными факторами распространения инноваций являются образование и доход: идеей потребления табака, а потом идеей здорового образа жизни как инновацией быстрее проникаются более богатые и образованные люди (Pampel 2005). Мы полагаем, что Интернет может выполнять роль одного из катализаторов процесса инновационной диффузии, который помогает быстрее распространить в обществе ту или иную ролевую модель.

Среди барьеров распространения телемедицины, которая может принести позитивные результаты, выделяются формальные и неформальные институциональные барьеры, в частности низкий уровень доверия населения и отсутствия у людей навыков получения таких услуг (Kalabikhina, Matyushina 2018).

Важно учитывать также уровень экономического развития стран и образования населения, в зависимости от которых степень влияния Интернета на здоровье может сильно различаться. В работе (Loader 1998) говорится о феномене «цифрового разрыва» (digital divide) между более и менее развитыми странами, за которым стоит различие в уровне грамотности в странах. В менее развитых странах население изначально менее грамотно в вопросах гигиены и профилактики болезней, что обеспечивает улучшение здоровья населения за счёт просветительского эффекта Интернета в этих вопросах, чему способствует усиление цифровизации в данной группе стран (так, например, найдены значимые свидетельства противодействия при помощи медицинских СМС-оповещений туберкулёзу в Камбодже и Южной Африке (Kahn 2004; Choun et al. 2017) и СПИДу в странах Северной Африки (Barninghausen et al. 2011)). В более же развитых странах, где Интернет распространён среди населения существенно более широко, а уровень образования населения выше, ресурсы Интернета становятся для населения чем-то обыденным, ослабляя полезный эффект от просвещения. Так в работе (Bessière et al. 2010) в регрессионной модели с лагированной зависимой переменной на данных панельного обследования США за 2000-2002 гг. не было обнаружено значимого влияния Интернета на изменение общего состояния здоровья на всех подвыборках по цели использования Интернета. А в исследовании (Tavares 2020) на основе упорядоченных логит-регрессий для индивидов в возрасте 50+ по перекрёстным данным 6-й волны SHARE (за 2015 г.) в европейских странах в кластере стран с более низким уровнем развития значимый эффект положительного влияния Интернета на здоровье был более значительным по величине, нежели в кластере более развитых стран. 
Хотя по классификации МВФ наша страна относится к числу развивающихся, всё же по значению индекса человеческого развития (ИЧР) за 2018 г. она входит в кластер стран с наиболее высоким его значением (0,8-1), что обусловливается в том числе и высоким уровнем образования населения. Это может говорить в пользу того, что значительный по величине эффект от информирования населения по вопросам социально значимых заболеваний касается, скорее, менее развитых стран (стран третьего мира), а для нашей страны не должен быть настолько же существенным.

С этим связан ограниченный набор рассматриваемых статей об эффектах воздействия Интернета на здоровье населения в развивающихся странах, поскольку мы считаем, что этот эффект будет разным для стран с высокообразованным и менее образованным населением. В странах с высокообразованным населением исследований о влиянии доступа к широкополосному Интернету на здоровье меньше, поскольку просветительский фактор ослабевает, связи становятся слабее и сложнее. Однако мы уверены в том, что выделение такого влияния может сделать разработку демографической политики более аргументированной и адресной.

В России в последнее десятилетие произошел скачок в распространении широкополосного Интернета, однако исследований влияния доступа к Интернету на здоровье населения с использованием индивидуальных микроданных пока не выполнено.

Наш исследовательский интерес заключается в оценке влияния Интернета на состояние здоровья индивида и на его самосохранительное поведение в области сокращения вредных привычек (снижения потребления табака и алкоголя) в России.

В исследовании сформулированы следующие гипотезы:

1. относительно частое использование высокоскоростного Интернета способствует улучшению состояния здоровья;

2. относительно частое использование высокоскоростного Интернета способствует снижению потребления табака;

3. относительно частое использование высокоскоростного Интернета способствует снижению потребления алкоголя.

\section{ДАННЫЕ И МЕТОДЫ}

Эмпирическая часть работы, посвященная анализу влияния доступа к Интернету на состояние здоровья и самосохранительное поведение людей, опирается на данные Комплексного обследования уровня жизни населения (КОУЖ), волны 2014, 2016, 2018 г. (Федеральная служба государственной... 2014, 2016, 2018).

Состояние здоровья оценивается нами на основе самоопределения. Хотя мы и выделили в нашей схеме потенциального воздействия Интернета на здоровье населения отдельно непосредственно уровень здоровья человека и уровень его самооценки здоровья, в данной работе мы принимаем условие, что самооценка индивида не отличается от состояния здоровья (такая гипотеза продиктована наличием имеющихся данных и опытом многих исследователей по изучению здоровья на основе самооценки (Кузьмич, Рощин 
2008; Назаров, Дормидонтова, Ляшок 2014; Ляшок, Рощин 2015; Bessière et al. 2010; Tavares 2020).

Индикаторы самосохранительного поведения, которые мы можем оценить, потребление табака и алкоголя. Разумеется, множество компонентов понятия самосохранительного поведения выглядит значительно шире, однако их использование в нашей работе ограничено возможностями информационной базы исследования. Было бы ценным для дальнейшей разработки темы, например, исследовать связь характеристик режима питания с использованием Интернета: в частности, систематическое питание всухомятку в процессе продолжительного пребывания в Интернете может нести риски для состояния здоровья. Однако переменные режима питания в КОУЖ отсутствуют. Из российских выборочных обследований их можно встретить в обследовании поведенческих факторов (ВНПФ) и в обследовании рациона питания (ВНРП). Но, к сожалению, ни в одном из двух указанных обследований нельзя обнаружить переменные, характеризующие использование Интернета. По аналогичной причине за кадром остаются и факторы нарушения гигиены труда (например, систематически недостаточная освещённость и проветриваемость помещения, а также неправильная дистанция до клавиатуры и экрана и нарушения рекомендуемой рабочей позы с недостаточной частотой перерывов).

Измерение потребления табака, и особенно алкоголя по данным социологических опросов имеет свои ограничения. Например, респонденты, особенно женщины и подростки, склонны фальсифицировать данные, касающиеся потребления табачной и алкогольной продукции. Это может приводить к смещённым результатам. Также деление алкоголя на пиво, вино и водку не позволяет охватить всю широту перечня спиртосодержащей продукции, что может приводить к искажениям в оценках. По словам авторов работы (Leon, Shkolnikov, McKee 2009), разнообразие источников этанола в России настолько широко, что данные по потреблению большинства из них могут и не находиться в базах. И КОУЖ в полной мере отражает эти ограничения. Кроме того, данные КОУЖ по объёму курения не предполагают дифференциации по различным видам табачной продукции, что не даёт возможности оценить влияние Интернета на изменение структуры спроса на отдельные виды табачной продукции (например, перехода на более лёгкие сигареты), если таковое имеет место. В КОУЖ переменные, отвечающие за потребление отдельных видов алкоголя, варьируются от полного отсутствия употребления до употребления каждый или почти каждый день. Это не даёт возможности оценить актуальные для респондентов модели потребления алкоголя (Насколько часто алкоголь потребляется в течение дня? Насколько много за один раз?).

В работах российских исследователей по факторам табакокурения и потребления алкоголя чаще используются микроданные РМЭЗ НИУ ВШЭ (где данные несколько чувствительней к моделям потребления, хотя также содержат много ограничений). Однако мы сделали выбор в пользу данных КОУЖ, поскольку эта база содержит более полную информацию об использовании Интернета: не только данные о наличии домашнего Интернета, но и информацию о частоте его использования. 
Выбор периода связан с тем, что доступ к высокоскоростному Интернету в России достиг стадии широкого распространения после 2013 г. (рисунок 1). На данных Единой межведомственной информационно-статистической системы (ЕМИСС) мы можем видеть монотонное увеличение доли населения, имеющего доступ к личному Интернету, с 61,4\% на 20 процентных пунктов за последние 6 лет. Исходя из этого нам представляется оптимальным использовать данные КОУЖ, начиная со второй волны (2014 г.), когда охват населения домашним Интернетом обеспечивал бы достаточный для получения надёжных результатов объём выборки, в которой примерно 2 из 3 респондентов имеют личный доступ к сети Интернет.

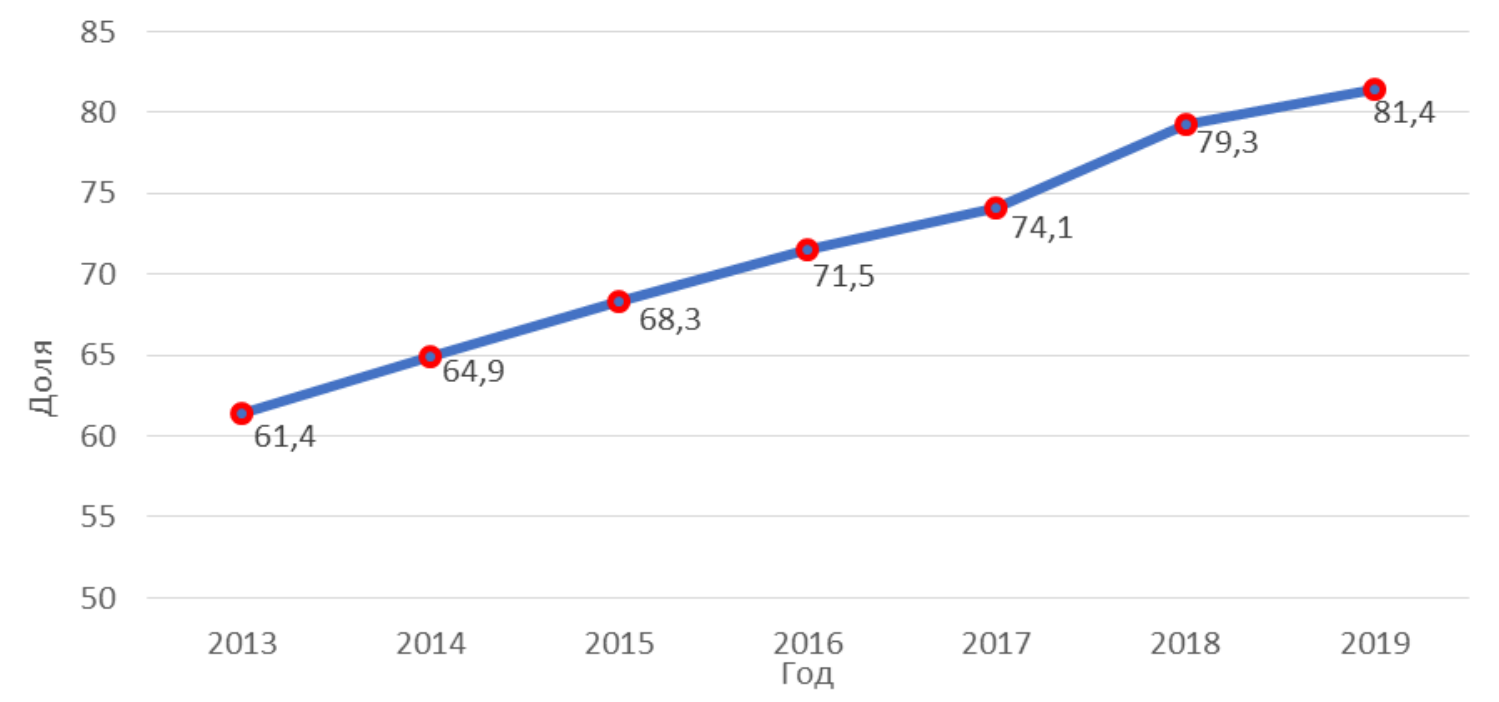

\section{Рисунок 1. Доля населения, являющегося активными пользователями сети} Интернет, в общей численности населения РФ, 2013-2019, \%

Источник: Построено авторами на основе данных (ЕМИСС 2020).

Модели оцениваются раздельно для обоих полов, поскольку, как было сказано ранее, женщины и мужчины по-разному оценивают свое здоровье и отличаются в моделях потребления табака и алкоголя. Значения зависимой переменной, переменных интереса и контрольных переменных упорядочены по возрастанию от меньшего к большему для удобства интерпретации последующих результатов. В среднем, на одну модель, в зависимости от количества валидных наблюдений, приходится от 30000 до 50000 наблюдений в моделях с кросс-секционными и панельными данными, и от 8000 до 38000 в моделях в первых разностях (по причине большого количества пропусков, делающих невозможным расчёт соответствующих разностей).

Выбор эмпирической стратегии различается в зависимости от характера данных по тому или иному фактору самосохранительного поведения. Для оценки же влияния частоты пользования Интернетом на самооценку здоровья используются модели упорядоченного выбора (на основе упорядоченной логит- и пробит-моделей), поскольку зависимая переменная самооценки здоровья выражена в порядковой шкале.

В моделях влияния частоты пользования Интернетом на объёмы курения и потребления алкогольной продукции различных видов (пиво, вино, водка) основу для проведения регрессионного анализа составляет тобит-модель. Выбор в пользу неё связан 
с условным характером зависимых переменных (у нас нет возможности получить данные об интенсивности курения, если респондент не курит, или потребления пива, вина или водки, если он не пьёт). Это накладывает на модель требование цензурировать данные, присвоив 0 в качестве значения объясняющей переменной тем респондентам, которые не являются курящими/пьющими людьми. В противном случае использование обычного метода наименьших квадратов (МНК) давало бы нам смещённые и несостоятельные оценки коэффициентов при переменных интереса.

В моделях используется следующий набор контрольных переменных: уровень образования, возраст, квадрат возраста, семейное положение, число детей, статус на рынке труда, логарифм уровня дохода, местность проживания (город/село), региональные эффекты. Описание переменных, использованных в работе, см. в Приложении 1. Стандартные ошибки задаются как робастные с поправкой на возможную гетероскедастичность.

Все коэффициенты корреляции (таблица 2) принимают значения, меньшие 0,5, что говорит в пользу отсутствия серьёзной угрозы мультиколлинеарности в случае совместного использования регрессоров в модели. Почти все из них являются значимыми на 1\%-ном уровне, исключение составляют коэффициенты корреляции логарифма дохода с курением и потреблением водки (оба значимы на 5\%-ном уровне), а также между местом проживания (город/село) и переменной курения, который оказался незначимым. Наибольшее значение принимает коэффициент между уровнем здоровья и возрастом индивида $(-0,4576)$, что очевидным образом объясняется тем, что в течение жизни здоровье человека склонно ухудшаться.

Таблица 2. Корреляционная матрица переменных

\begin{tabular}{|c|c|c|c|c|c|c|c|}
\hline & Курение & Здоровье & Вино & Водка & Пиво & Интернет & $\begin{array}{c}\text { Уровень } \\
\text { образования }\end{array}$ \\
\hline Курение & 1,0000 & & & & & & \\
\hline Здоровье & 0,0405 & 1,0000 & & & & & \\
\hline Вино & $-0,1308$ & 0,0191 & 1,0000 & & & & \\
\hline Водка & 0,3820 & $-0,0401$ & $-0,0489$ & 1,0000 & & & \\
\hline Пиво & 0,3956 & 0,1240 & 0,0209 & 0,3621 & 1,0000 & & \\
\hline Интернет & $-0,0501$ & 0,2101 & 0,0866 & $-0,0862$ & 0,0549 & 1,0000 & \\
\hline $\begin{array}{l}\text { Уровень } \\
\text { образования }\end{array}$ & $-0,2020$ & 0,0499 & 0,1220 & $-0,0778$ & $-0,1264$ & 0,2058 & 1,0000 \\
\hline Возраст & $-0,0825$ & $-0,4576$ & $-0,0118$ & 0,1277 & $-0,2040$ & $-0,3469$ & 0,0685 \\
\hline Женат или замужем & 0,0377 & $-0,0548$ & $-0,0525$ & 0,0883 & 0,0206 & $-0,0839$ & 0,0508 \\
\hline Логарифм дохода & $-0,0184$ & 0,0726 & 0,1458 & 0,0752 & 0,0215 & 0,1444 & 0,2910 \\
\hline Город & $-0,0125$ & 0,0417 & 0,0804 & 0,0024 & 0,0180 & 0,1163 & 0,1678 \\
\hline Число детей & 0,0330 & 0,1219 & $-0,0367$ & $-0,0503$ & 0,0425 & 0,0449 & $-0,0284$ \\
\hline & Возраст & \multicolumn{2}{|c|}{ Женат или замужем } & \multicolumn{2}{|c|}{ Логарифм дохода } & Город & Число детей \\
\hline Возраст & 1,0000 & & & & & & \\
\hline Женат или замужем & 0,1214 & \multicolumn{2}{|c|}{1,0000} & & & & \\
\hline Логарифм дохода & 0,1336 & \multirow{2}{*}{\multicolumn{2}{|c|}{$\begin{array}{l}-0,1062 \\
-0,0244\end{array}$}} & \multicolumn{2}{|c|}{1,0000} & & \\
\hline Город & $-0,0171$ & & & \multicolumn{2}{|c|}{0,2821} & 1,0000 & \\
\hline Число детей & $-0,3115$ & \multicolumn{2}{|c|}{$\begin{array}{r}-0,0244 \\
0,2437\end{array}$} & \multicolumn{2}{|c|}{$-0,4496$} & $-0,0769$ & 1,0000 \\
\hline
\end{tabular}

Источник: Построено авторами в программном пакете Stata 14.2 на данных (Федеральная служба государственной... 2014, 2016, 2018).

Примечание: Описание переменных, использованных в работе, см. в Приложении 1. 
Из набора значений объясняющей переменной мы исключаем индивидов, не пользующихся Интернетом, во избежание смещения оценок. Из данных КОУЖ (рисунок 2) следует, что доля респондентов, не имеющих домашнего доступа к Интернету, за период обследования 2014-2018 г. монотонно снижалась с 7,8 до 0,7\%.

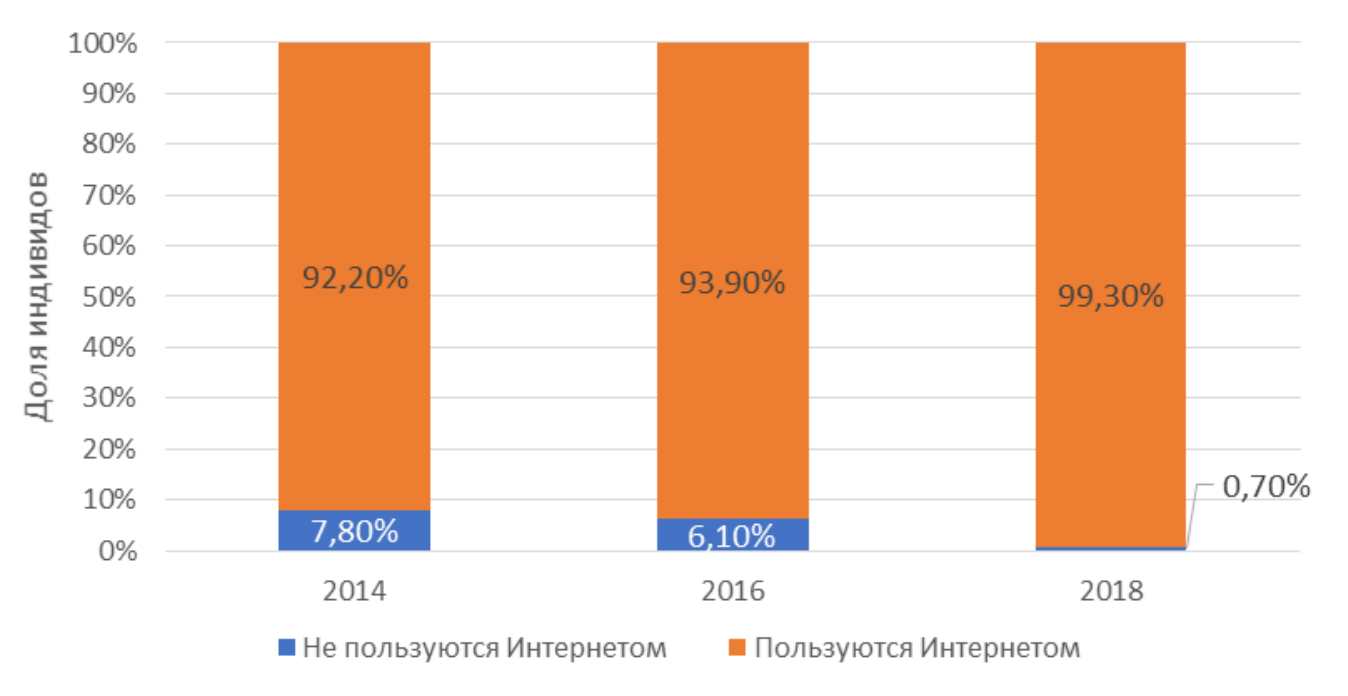

Рисунок 2. Доля лиц, которые указали, что пользуются/не пользуются Интернетом, из общего числа опрошенных в данную волну

Источник: Построено авторами на основе данных (Федеральная служба государственной... 2014, 2016, 2018).

Примечание: Показатель рассчитан при помощии программного пакета Stata 14.2.

Для начала мы строим модели на основе кросс-секционных данных на выборке за 2018 г. Результаты подвергаются проверке на робастность по следующим направлениям:

- использование данных более ранних волн (за 2016 и 2014 г.);

- комбинирование различных наборов контрольных переменных (например, включение/исключение из модели региональных эффектов);

- использование альтернативных типов моделей (например, вместо тобитмоделей - модели на основе логита, пробита и МНК, а также модель с использованием линейных стандартных ошибок).

Результаты применения простой упорядоченной пробит-модели для оценки состояния здоровья могут быть подвергнуты угрозе получения несостоятельных оценок изза двусторонней причинно-следственной связи между уровнем здоровья индивида (на основе самооценки здоровья) и частотой его выхода в Интернет. То есть, положительный знак коэффициента между переменными здоровья и частоты использования Интернета может объясняться не только влиянием последнего на здоровье (удобнее записываться к врачу, заказывать лекарства, получать дистанционные советы по профилактике и лечению заболеваний, дистанционную паллиативную помощь и другие услуги телемедицины), но и, напротив, влиянием здоровья на частоту пользования Интернетом (более высокий объём капитала здоровья может давать индивиду физическую возможность пользоваться Интернетом более часто и продолжительно). 
Для устранения эндогенности из-за двусторонней причинно-следственной связи очевидна необходимость подбора такого параметра, который бы коррелировал с частотой пользования Интернетом, но при этом не коррелировал со здоровьем. В КОУЖ есть переменная частоты общения в Интернете. Она очевидным образом коррелирована с частотой пользования Интернетом (чтобы чаще общаться, нужно чаще заходить в сеть), коррелированность со здоровьем (экзогенность инструмента) можно проверить при помощи теста Саргана (Sargan 1958). Стоит отметить, что такой подход, хоть и избавляет нас от селективности внутри выборки (связанной с тем, что чаще сидят в Интернете те, кому это больше позволяет здоровье), однако всё же не может устранить её в полной мере из-за наличия возможной угрозы внешнего самоотбора. А именно, изначально в выборку могут не попадать люди с низшим социально-экономическим статусом, которые одновременно не пользуются Интернетом и могут отличаться более рисковым поведением. С этим несовершенством информационной базы мы вынуждены мириться за неимением других данных.

Чтобы очистить прямое влияние Интернета на здоровье от обратного влияния, модели повторно оцениваются при помощи инструментального подхода с использованием частоты общения в Интернете. B пакете Stata 14.2 отсутствуют технические возможности для проведения диагностики валидности инструментов для упорядоченной пробит-модели, однако есть возможность провести её для бинарной пробит-модели, поэтому зависимая переменная переводится в бинарный вид: создаётся переменная «хорошее здоровье», которой присваивается значение «1», если респондент характеризовал своё здоровье как «хорошее» или «очень хорошее», и «0»- иначе.

В ходе диагностики подтверждается, что валидность частоты общения в Интернете как инструмента обосновывается её релевантностью (чтобы чаще общаться в Интернете, необходимо чаще заходить в сеть, тест на слабые инструменты) и экзогенностью (тест Саргана) (см. Приложение 3).

Добавим некоторые методические замечания и для оценки самосохранительного поведения. Оценка влияния частоты пользования Интернетом на объёмы курения на перекрёстных данных может дать нам информацию о том, кто, в среднем, курит больше: люди, которые чаще или реже пользуются Интернетом. В то же время, чтобы надёжно утверждать, что Интернет способствует увеличению или уменьшению потребления табачной продукции, нам необходимо быть уверенными, что в модели отсутствует эндогенность. Одной из причин возможной эндогенности может быть недоучёт факторов социопсихологической природы (June et al. 2007), которые могут подвергать индивида аддикциям (одновременно зависимости от Интернета и курения) и которые при этом сложно наблюдать в явном виде.

В связи с этим мы проводим повторную оценку влияния частоты пользования Интернетом на параметры самосохранительного поведения при помощи тобит-моделей в первых разностях. Это может позволить свести на нет влияние ненаблюдаемых социальнопсихологических особенностей, если предположить, что эти особенности для каждого человека носят устойчивый во времени характер (алгебраически это будет означать, что 
первые разности переменных, которые отражают социально-психологические особенности, превратятся в 0$)$.

Мы оцениваем ряд моделей отдельно для каждого параметра самосохранительного поведения (курение, потребление пива, водки, вина). Также модели дезагрегируются по полу, оцениваются модели с региональными эффектами и без их учёта. В дополнение к основным моделям переменная частоты использования Интернета рассматривается нелинейно (с квадратом данной переменной и как индикаторы отдельных категорий частоты входа в Интернет) на случай возможного наличия точек перегиба кривых зависимости здоровья и объёмов курения и потребления алкоголя от Интернета.

\section{РЕЗУЛЬТАТЫ: ВЛИЯНИЕ ИНТЕРНЕТА НА САМООЦЕНКУ ЗДОРОВЬЯ}

Модели на основе инструментального подхода демонстрируют положительное влияние частоты использования Интернета на здоровье (таблица 3) на 5\%-ном и 10\%-ном уровнях значимости в разных спецификациях. Отметим, что в таблице 3 представлены предельные эффекты, а не коэффициенты моделей, что позволяет нам судить не только о направлении влияния частоты использования Интернета на здоровье, но и о величине этого влияния.

Таблица 3. Результаты регрессионного анализа влияния Интернета на здоровье

\begin{tabular}{|c|c|c|c|c|}
\hline Переменные & $\begin{array}{c}\text { Модель 1, } \\
\text { Бинарный пробит } \\
\text { (женщины) }\end{array}$ & $\begin{array}{c}\text { Модель 2, } \\
\text { Бинарный пробит } \\
\text { (мужчины) }\end{array}$ & $\begin{array}{c}\text { Модель 3, } \\
\text { Бинарный пробит } \\
\text { (женщины) }\end{array}$ & $\begin{array}{c}\text { Модель 4, } \\
\text { Бинарный пробит } \\
\text { (мужчины) }\end{array}$ \\
\hline Интернет & $\begin{array}{r}0,0566^{* *} \\
(0,0222)\end{array}$ & $\begin{array}{l}0,0644 * \\
(0,0332)\end{array}$ & $\begin{array}{r}0,0565^{* *} \\
(0,0227)\end{array}$ & $\begin{array}{l}0,0613 * \\
(0,0341)\end{array}$ \\
\hline Уровень образования & $\begin{array}{l}0,0384 * * * \\
(0,00595)\end{array}$ & $\begin{array}{l}0,0263 * * * \\
(0,00889)\end{array}$ & $\begin{array}{l}0,0385 * * * \\
(0,00607)\end{array}$ & $\begin{array}{l}0,0259 * * * \\
(0,00916)\end{array}$ \\
\hline Женат или замужем & $\begin{array}{c}0,0860 * * * \\
(0,0220)\end{array}$ & $\begin{array}{l}0,0819^{*} \\
(0,0421)\end{array}$ & $\begin{array}{c}0,0969 * * * \\
(0,0223)\end{array}$ & $\begin{array}{l}0,0900 * * \\
(0,0430)\end{array}$ \\
\hline Логарифм дохода & $\begin{array}{c}0,274 * * * \\
(0,0225)\end{array}$ & $\begin{array}{c}0,281 * * * \\
(0,0331)\end{array}$ & $\begin{array}{c}0,287 * * * \\
(0,0264)\end{array}$ & $\begin{array}{c}0,292 * * * \\
(0,0389)\end{array}$ \\
\hline Город & $\begin{array}{c}-0,108 * * * \\
(0,0257)\end{array}$ & $\begin{array}{c}-0,136 * * * \\
(0,0387)\end{array}$ & $\begin{array}{c}-0,116 * * * \\
(0,0266)\end{array}$ & $\begin{array}{c}-0,131 * * * \\
(0,0405)\end{array}$ \\
\hline Число детей & $\begin{array}{l}0,146 * * * \\
(0,0183)\end{array}$ & $\begin{array}{l}0,147 * * * \\
(0,0270)\end{array}$ & $\begin{array}{l}0,149 * * * \\
(0,0190)\end{array}$ & $\begin{array}{l}0,137 * * * \\
(0,0282)\end{array}$ \\
\hline Занятый & $\begin{array}{c}0,376 * * * \\
(0,0255)\end{array}$ & $\begin{array}{c}0,720 * * * \\
(0,0404)\end{array}$ & $\begin{array}{c}0,380 * * * \\
(0,0260)\end{array}$ & $\begin{array}{c}0,739 * * * \\
(0,0416)\end{array}$ \\
\hline Возраст & $\begin{array}{c}-0,0328 * * * \\
(0,00541)\end{array}$ & $\begin{array}{c}-0,0588 * * * \\
(0,00746)\end{array}$ & $\begin{array}{c}-0,0343 * * * \\
(0,00548)\end{array}$ & $\begin{array}{c}-0,0612 * * * \\
(0,00761)\end{array}$ \\
\hline Возраст ${ }^{2}$ & $\begin{array}{c}7,17 * 10^{-5} \\
\left(5,56 * 10^{-5}\right)\end{array}$ & $\begin{array}{c}0,000394 * * * \\
\left(7,79 * 10^{-5}\right)\end{array}$ & $\begin{array}{l}8,42 * 10^{-5} \\
\left(5,63 * 10^{-5}\right)\end{array}$ & $\begin{array}{c}0,000411^{* * *} \\
\left(7,94 * 10^{-5}\right)\end{array}$ \\
\hline Константа & $\begin{array}{l}-0,176 \\
(0,254)\end{array}$ & $\begin{array}{l}0,0969 \\
(0,354)\end{array}$ & $\begin{array}{c}-0,635 * * \\
(0,319)\end{array}$ & $\begin{array}{l}-0,311 \\
(0,462)\end{array}$ \\
\hline $\begin{array}{l}\text { Региональные эффекты } \\
\text { Число наблюдений }\end{array}$ & $\begin{array}{c}\text { Нет } \\
52,238\end{array}$ & $\begin{array}{c}\text { Нет } \\
30,818\end{array}$ & $\begin{array}{c}\text { Есть } \\
52,238\end{array}$ & $\begin{array}{c}\text { Есть } \\
30,818\end{array}$ \\
\hline
\end{tabular}

Источник: Построено авторами в программном пакете Stata 14.2.

Зависимая переменная: хорошее здоровье, в таблице указаны предельные эффекты

Примечание: Построено авторами в программном пакете Stata 14.2. Значимость: *-10\%, **_5\%, $* * *-1 \%$. 
Полученные значения предельных эффектов говорят о том, что переход на новую ступень, характеризующуюся более частым использованием Интернета, в среднем повышает вероятность, что респондент мужского пола отметит у себя хорошее здоровье, на 6,44 процентных пункта, а респондент женского пола - на 5,66 п.п. Отметим, что при добавлении региональных эффектов оценённая величина влияния Интернета на здоровье сокращается весьма незначительно - до 6,13 п.п. для мужчин и до 5,65 п.п. для женщин.

Возможные интерпретации (со стороны позитивного влияния на здоровье):

1) Интернет повышает доступность медицинских услуг (дистанционной записи к врачу, заказа лекарств, получения дистанционных советов по профилактике и лечению заболеваний, второго диагноза, других услуг телемедицины);

2) Интернет повышает доступ к другим дистанционным услугам, экономит время и силы на поиск и доставку товаров;

3) Интернет повышает доступ к дистанционной занятости, респондент не тратит здоровье по дороге на работу и с работы;

4) Интернет играет позитивную просветительскую роль в вопросах о здоровом образе жизни, позволяет найти информацию об услугах, связанных со здоровым образом жизни;

5) Интернет разнообразит досуг, увеличивает возможности общения для (пожилых) людей, что улучшает психическое здоровье.

Возможные интерпретации (со стороны позитивного влияния на самооценку здоровья): Интернет позволяет лучше позиционировать свое состояние по отношению к другим людям в результате обилия доступных кейсов (в том числе и тяжелобольным).

В дополнение: образование, доход, число детей, брачный статус положительно влияют на самооценку здоровья, проживание в городе - отрицательно. Переменная возраста влияет ожидаемо: чем старше человек, тем хуже его здоровье.

Полученные результаты воспроизводятся в моделях с нелинейной объясняющей переменной. При этом коэффициент при переменной квадрата частоты использования Интернета значим и имеет отрицательный знак, а коэффициенты категорий частоты входа в Интернет значимы, положительны и убывают по значению по мере повышения частоты пребывания в Интернете в сравнении с группой с наименьшей частотой входа в Сеть. Это значит, что положительное влияние Интернета на здоровье монотонно убывает, но при максимальной частоте входа в Интернет всё же не достигается точка перелома, начиная с которой более частое использование Интернета становится значимо пагубным для здоровья.

Строго говоря, полученные результаты в силу специфики использованных данных и методологии позволяют нам дать оценку влияния Интернета только на усреднённого респондента. Проделанная работа представляет собой лишь начальный этап разработки темы влияния цифровизации на самосохранительное поведение людей и здоровье, поэтому рассмотрение Интернета в более развёрнутом виде с учётом многообразия его ресурсов, функций, опций, систем их организации, а также способов его использования существенно ограничено как масштабом исследования, так и, опять же, возможностями 
информационной базы. Частично в КОУЖ для расширения исследования предложена палитра вопросов о причинах использования Интернета, содержащая 11 вариантов ${ }^{2}$, однако ответы на вопрос не имеют пересечений, что не совсем корректно, поскольку Интернет может использоваться одним и тем же человеком в разное время и для дистанционной работы, и для просмотра новостных материалов, и как форма досуга, и по иному назначению. Также не исключен вариант, что человек может заходить в Сеть по инерции, не преследуя в момент входа определённой цели. Несмотря на несовершенства таких вопросов, были оценены инструментальные пробит-модели на 22 подвыборках (11 целей входа * 2 гендера). Ни в одной из подгрупп влияние Интернета на самооценку здоровья не носит отрицательного характера. Положительная связь наблюдается в подгруппах женщин, заходящих в Интернет с целью выполнения оплачиваемой работы, общения в социальных сетях и скачивания музыки и фильмов, и в подгруппах мужчин, заходящих в Сеть для поиска вакансий и клиентов, поиска и заказа товаров и услуг, продажи личных вещей и имущества, а также прочтения новостей. Результаты воспроизводятся в аналогичных моделях с региональными эффектами, за исключением модели с мужчинами, заходящими в Сеть с целью прочтения новостей, в которой коэффициент при переменной частоты входа в Интернет балансирует на грани 10\%-ной значимости.

Полученные результаты позволяют давать следующие объяснения, почему люди, которые чаще заходят в Сеть, лучше оценивают своё здоровье:

1) развитие возможностей дистанционной занятости. По-видимому, этот канал в настоящее время больше касается женщин, у которых с развитием Интернета появляется больше возможностей совмещать оплачиваемый труд на рынке труда и неоплачиваемый труд в домохозяйстве: совмещение домашних забот с дистанционной занятостью благотворно сказывается как на физическом (за счёт сокращения объёмов и длительности деловых поездок, которые могут выматывать индивидов), так и на психическом состоянии здоровья (удовлетворённость трудом) и на экономическом положении индивида (автономный источник доходных поступлений);

2) расширение возможностей досуговой деятельности - развитие новых ресурсов коммуникационной (общение в социальных сетях) и развлекательной деятельности (просмотр и скачивание фильмов, игр, музыки) благотворно сказывается на психическом здоровье респондентов;

3) снижение трансакционных издержек в торгово-предпринимательской деятельности развитие электронных средств привлечения клиентов и подбора контрагентов также может позитивно влиять на восприятие собственного здоровья как с физической, так и с психической стороны, сберегая психофизические ресурсы индивидов за счёт

\footnotetext{
2 В перечень включены: 1) выполнение оплачиваемой работы; 2) поиск вакансий, клиентов, рассылка информации; 3) получение информации, оформление документов на сайтах органов государственной власти; 4) поиск и заказ товаров и услуг, продажа личных вещей и имущества; 5) осуществление финансовых операций; 6) дистанционное обучение; 7) пользование электронными библиотеками, энциклопедиями, виртуальными экскурсиями и др.; 8) прочтение новостной информации; 9) общение в социальных сетях; 10) обсуждение социальных и политических вопросов; 11) скачивание фильмов, музыки, игр и др.
} 
сокращения объёма контактов с неподходящими участниками сделки, а также числа и продолжительности деловых поездок.

Однако к таким данным можно предъявить претензии: 1) усыхание выборки (разброс валидных наблюдений составил от 5 до 30 тыс., при этом в ряде моделей серьёзно снизилась представительность данных по регионам, иногда вплоть до пропущенных данных по более чем половине регионов, что ставит под сомнение незначимость большинства результатов по подвыборкам); 2) неучёт в списке целей в явном виде информационно-просветительской функции Интернета в области медицины (это позволяет нам только догадываться, но не строго утверждать, что, помимо благотворного влияния Интернета на психическое здоровье, за данными скрывается влияние информации о профилактике и лечении заболеваний, а также телемедицины, поскольку такая причина посещения Сети может быть побочной для всех присутствующих в линейке целей в КОУЖ).

В то же время для практики полученные результаты не в полной мере бесполезны: на данных выявлена положительная взаимосвязь между частотой использования Интернета и самооценкой здоровья и установлено, что положительный знак коэффициента не обусловлен обратной причинно-следственной связью (в противном случае в модели с инструментальной переменной влияние Интернета на здоровье носило бы незначимый характер, но в нашем случае это было не так). Это говорит о том, что в использованных данных, по крайней мере, присутствуют работоспособные каналы влияния Интернета на здоровье, более надёжное выявление которых в будущем могло бы иметь практическое значение для укрепления здоровья и повышения эффективности использования Интернета в России.

\section{РЕЗУЛЬТАТЫ: ВЛИЯНИЕ ИНТЕРНЕТА НА ПОТРЕБЛЕНИЕ ТАБАКА И АЛкогОЛЯ}

Для удобства изложения мы вынесли таблицы с результатами регрессионного анализа в этой части в Приложение 2, здесь же перечислим основные результаты:

1) мужчины, которые чаще пользуются Интернетом, при прочих равных условиях, в среднем: меньше курят, меньше пьют алкоголя в целом, меньше пьют водки в частности, чаще пьют вино, то есть являются пионерами перехода, на европейскую модель потребления алкоголя;

2) женщины, которые чаще пользуются Интернетом, при прочих равных условиях, в среднем: больше курят, больше пьют алкоголя в целом (всех его видов).

Основные результаты тобит-моделей на кросс-секционных данных и в первых разностях совпадают.

Полученные результаты, впрочем, следует трактовать с некоторой осторожностью, напоминаем, что измерение частоты и объемов потребления табака и алкоголя (особенно у женщин) может не отражать действительность в полной мере. Тем не менее попробуем представить несколько интерпретаций полученных результатов. 
Первый результат подтверждает соответствующие исходные гипотезы для респондентов мужского пола о снижении потребления алкоголя и табака.

Более того, Интернет может способствовать замещению крепких напитков лёгкими. Культурно-исторический, социально-экономический и политический опыт, описанный в работе (Заиграев 2009) и подтверждённый эмпирическими оценками потребления алкоголя в России (Немцов 2014), сформировал в России довольно рискованную модель потребления, которую можно назвать моделью потребления северного типа (Бойцов, Самородская, Семенов 2016). Основной чертой северной модели является преобладание в общей структуре потребления крепких спиртных напитков. Северной модели потребления алкоголя противопоставляется европейская модель, в которой производство и потребление более лёгких алкогольных напитков является преобладающим. Полученные нами оценки позволяют предполагать, что Интернет способствует этому переходу у мужчин.

Полученный результат требует дополнительного исследования о причинах такого воздействия: возможно, Интернет используется респондентами мужского пола как источник заработка, что увеличивает для них экономическую доступность более дорогостоящих элитных напитков, которые являются слабоалкогольными. Также возможно, что Интернет может использоваться ими как альтернативный по отношению к алкоголю способ снятия стресса (возможность «выговориться» в сетевом общении, «отвести душу» путём социальных провокаций на условиях анонимности персональных данных). Компьютерные игры для мужчин могут быть заместителем крепкого алкоголя в качестве альтернативной формы проведения досуга.

Второй результат опровергает наши исходные гипотезы для респондентов женского пола о снижении потребления алкоголя и табака. Однако окончательный вывод мы не торопимся делать, поскольку данные не предполагают дифференциации по отдельным видам табачной продукции, по объему и таймингу потребления алкоголя. Кроме того, индивиды склонны фальсифицировать данные, касающиеся алкогольной продукции и табакокурения (причем женщины, видимо, чаще и сильнее, чем мужчины). Наконец, процесс развития цифровизации в стране совпал со сменой поколений: В. Радаев (2020) на данных РМЭЗ НИУ ВШЭ получил результат, что нынешнее молодое поколение миллениалов в среднем менее склонно к потреблению алкогольной и табачной продукции, нежели предыдущие. Доказать однозначно на имеющихся данных приоритет меняющегося потребительского поведения, который создает и спрос на цифру, или, напротив, приоритет цифровизации, которая создала альтернативный досуг, не представляется возможным. Чтобы более надёжно отделить поколенческий эффект от собственно влияния Интернета на потребление алкоголя и табака, было бы желательно использовать более длинные ряды данных, однако: 1) КОУЖ не располагает более отдалёнными данными ранее 2014 г. с большим количеством валидных наблюдений; 2) данные РМЭЗ НИУ ВШЭ, несмотря на их большую протяжённость во времени (ежегодно почти каждый год с 1994 г.), не содержат вопроса о частоте использования Интернета, а только о его наличии в домохозяйстве; 3) явление тотальной цифровизации в РФ само по себе достаточно молодое и исчисляется, как было показано ранее, не более чем одним десятком лет. Поэтому по этой части исследования мы делаем выводы с особенной осторожностью. 
Если предположить, что данные по мужчинам и женщинам имеют схожие ограничения, то мы можем выдвинуть две идеи по поводу интерпретации результатов. Во-первых, можно предположить, что такой результат вызван продолжительным пребыванием женщин во второй фазе табачного перехода, когда рост объёмов женского курения обусловливается мотивом стремления к гендерному «равенству» и оно понимается как принятие мужского типа поведения. В таком случае Интернет может усиливать эгалитарные настроения женщин в силу ассоциации Интернета с пространством, свободным от предписаний, в том числе гендерного характера. Как следствие это может приводить к повышению объёмов женского курения, потребления пива и вина. Во-вторых, в отличие от мужчин, для женщин Интернет не является заменителем «водочного» досуга. Видимо, женщины в меньшей степени играют в компьютерные игры, а также меньше пьют водку, этот замещающий досуговый канал у них не работает.

Еще один важный, на наш взгляд, вывод: наличие детей оказывает сдерживающее влияние как на мужчин, так и на женщин в отношении курения во всех моделях; на женщин - в моделях с региональными эффектами. Отдельно построены модели (см. таблицу П2.5 Приложения 2), в которых вместо числа детей использован построенный на его основе бинарный индикатор наличия детей в домохозяйстве. Как мы и предполагали, наличие детей оказывает значимое на $1 \%$-ном уровне сдерживающее влияние как на курение мужчин, так и на курение женщин во всех моделях.

\section{ЗАКЛЮЧЕНИЕ}

Подводя итог, можно сделать следующие выводы:

1) Интернет является значимым ресурсом для сохранения и преумножения капитала здоровья для обоих полов. Самооценка здоровья повышается у женщин и мужчин, пользующихся Интернетом (при прочих равных условиях);

2) мужчины, которые чаще пользуются Интернетом, при прочих равных условиях в среднем:

- меньше курят,

- меньше пьют алкоголя в целом,

- меньше пьют водки, в частности, чаще пьют вино, т. е. являются пионерами перехода с северной на европейскую модель потребления алкоголя,

- наличие детей оказывает сдерживающее влияние на мужчин в отношении курения;

3) женщины, которые чаще пользуются Интернетом, при прочих равных условиях в среднем:

- больше курят,

- больше пьют алкоголя (пива и вина),

- наличие детей оказывает сдерживающее влияние на женщин в отношении курения.

Первый вывод полностью подтверждает первую гипотезу анализа. На основании полученного результата мы можем предполагать, что полезный эффект от использования 
Интернета перекрывает возможное его пагубное влияние на здоровье индивида (в том числе, связанное с ненормированным использованием электронных средств, что мы не можем выявить по данным КОУЖ, не предоставляющим информацию о длительности использования электронных носителей).

Второй результат подтверждает соответствующие исходные гипотезы для респондентов мужского пола о снижении потребления алкоголя и табака при относительно частом использовании Интернета. Более того, Интернет может способствовать замещению крепких напитков лёгкими, т. е. усиливает переход от северной к европейской модели потребления алкоголя.

Третий результат опровергает соответствующие исходные гипотезы для респондентов женского пола о снижении потребления алкоголя и табака при относительно частом использовании Интернета. Возможно, это связано с тем, что данные по потреблению алкоголя и табака по женщинам менее достоверны, а возможно, с тем, что Интернет не является для женщин заменителем «водочного» досуга в отличие от мужчин. Стадия эмансипации женщин в современной России (приверженность мужскому поведению) тоже может влиять на положительную связь доступа к Интернету и потребление табака и слабого алкоголя.

В целом из проведённого анализа следует, что в России Интернет является, скорее, сберегающим здоровье фактором. Это означает, что расширение доступа к высокоскоростному Интернету может быть действенным инструментом укрепления здоровья жителей России.

\section{ЛИТЕРАТУРА}

Антонов А.И. (1989). Опыт исследования установок на здоровье и продолжительность жизни. Социальные проблемы здоровья и продолжительности жизни, 44. Москва.

Бойцов С.А., Самородская И.В., Семенов В.Ю. (2016). Влияние медицинских и немедицинских факторов на смертность населения: роль алкоголя. Социальная $u$ клиническая психиатрия, 26(2), 97-106.

Борисов В. (1999). Демография. Москва: Издательский дом «Nota Bene».

Вишневский В.М., Ляхов А.И., Портной С.Л., Шахнович И.Л. (2005). Широкополосные беспроводные сети передачи информации. Москва: Техносфера.

Груздева М. (2017). Инструменты формирования самосохранительных практик населения: социальные сети и блогосфера. Социальное пространство, 4(11), 5.

Демьянова А.А. (2005). Факторы и типы потребления алкоголя и табака в России. Экономическая сочиология, 6(1), 78-94.

Единая межведомственная информационно-статистическая система (ЕМИСС) (2020). Доля населения, являющихся активными пользователями сети Интернет, в общей численности населения РФ (2020). URL: https://www.fedstat.ru/indicator/43566 (данные загружены 02.05.2020).

Жеребин В., Алексеева О., Вершинская О. (2017). Социально-психологические особенности пользователей Интернета. Народонаселение, 1(75), 116-124. 
Заиграев Г.Г. (2009). Алкоголизм и пьянство в России: пути выхода из кризисной ситуации. Социологические исследования, 8, 74-84.

Калабихина И.Е. (2019). Демографические размышления о цифровой экономике. Вестник Московского Университета, 6(6), 147-166.

Калабихина И.Е., Кузнецова П.О. (2019). Гендерные аспекты табачной эпидемии в России. Журнал Новой экономической ассоџичаџии, 44(4), 161-187.

Калабугина Е.А. (2013). Влияние электронных средств на здоровье студентов. Вестник Южно-Уральского государственного университета. Серия: Образование.

Педагогические науки, 5(2), 67-73.

Кузьмич О., Рощин С. (2008). Лучше ли быть здоровым? Экономическая отдача от здоровья в России. Экономический журнал ВШЭ, 12(1), 29-55.

Ляшок В.Ю., Рощин С.Ю. (2015). Влияние здоровья на предложение труда пожилых. Прикладная эконометрика, 4 (40), 6-27.

Магнус Я.Р., Катышев П.К., Пересецкий А.А. (2004). Эконометрика. Начальный курс: учеб. 6-е изд., перераб. и доп. М.: Дело.

Медков В. (2002). Демография: учебное пособие. Серия «Учебники и учебные пособия». Ростов-на-Дону: Феникс.

Назаров В.С., Дормидонтова Ю.А., Ляшок В.Ю. (2014). Анализ факторов, влияющих на принятие решения о выходе на пенсию. Журнал Новой экономической ассоциациии, 4, 66-86.

Немцов А.В. (2014). Алкогольная ситуация в России. Собриология, 2(2), 13-19.

Радаев В.В. (2020). Миллениаль: Как меняется российское общество. 2 изд. Нац. исслед. ун-т «Высшая школа экономики». Москва: Изд. дом Высшей школы экономики.

Ревякин Е. (2006). Самосохранительное поведение: понятие и сущность. Вестник ИГЭУ, $1,1-4$.

Федеральная служба государственной статистики (Росстат) (2014). Комплексное обследование условий жизни населения. 2014 2.

Федеральная служба государственной статистики (Росстат) (2016). Комплексное обследование условий жизни населения. 2016 г.

Федеральная служба государственной статистики (Росстат) (2018). Комплексное обследование условий жизни населения. 2018 2.

Barnighausen T., Chaiyachati K., Chimbindi N., Peoples A., Haberer J., Newell M.L. (2011). Interventions to increase antiretroviral adherence in sub-Saharan Africa: A systematic review of evaluation studies. Lancet Infect. Dis., 11, 942-951

Bauer T., Göhlmann S., Sinning M. (2007). Gender differences in smoking behavior. Health Economics, 16(9), 895-909.

Bessière K., Pressman S., Kiesler S., Kraut R. (2010). Effects of internet use on health and depression: a longitudinal study. Journal of medical Internet research, 12(1). DOI: https://doi.org/10.2196/jmir.1149 (данные загружены 10.08.20).

Bundorf M.K., Wagner T.H., Singer S.J., Baker L.C. (2006). Who searches the internet for health information? Health Services Research, 41(3), 819-836. 
Cesare N., Lee H., McCormick T., Spiro E., Zagheni E. (2018). Promises and pitfalls of using digital traces for demographic research. Demography, 55(5), 1979-1999.

Choun K., Achanta S., Naik B., Tripathy J.P., Thai S., Lorent N., Khun K.E., Griensven J.V., Kumar A.M.V., Zachariah R. (2017). Using mobile phones to ensure that referred tuberculosis patients reach their treatment facilities: A call that makes a difference. Health Serv. Res., 17, 575.

DiMaggio P., Hargittai E., Neuman W.R., Robinson, J. P. (2001). Social Implications of the Internet. Annual Review of Sociology, 27(1), 307-336.

Feil E.G., Noell J., Lichtenstein E., Boles S.M., McKay H.G. (2003). Evaluation of an Internetbased smoking cessation program: Lessons learned from a pilot study. Nicotine \& Tobacco Research, 5(2), 189-194.

Grøtvedt L., Stavem K. (2005). Association between age, gender and reasons for smoking cessation. Scandinavian Journal of Public Health, 33(1), 72-76.

June K.J., Sohn S.Y., So A.Y., Yi G.M., Park S.H. (2007). A study of factors that influence Internet addiction, smoking, and drinking in high school students. Taehan Kanho Hakhoe chi, 37(6), 872-882.

Kahn T. (2004). Mobile Phones Keep Track of HIV Treatments. URL: http://www.scidev.net/global/ health/news/mobile-phones-keep-track-of-hiv-treatments.html (данные загружены 10.08.20).

Kalabikhina I., Matyushina D. (2018). A study of the population's attitude to telemedicine technologies on the example of online medical consultations. Population and Economics, ARPHA Platform, 2(2), 78-109.

Killian T.S. (2012). Health-information seeking on the Internet and current smoking status: Evidence from the national health interview survey. Open Journal of Preventive Medicine, 2(3), 291-298.

Kling R. (2000). Learning about information technologies and social change: The contribution of social informatics. Information Society, 16(3), 217-232.

Leon D.A., Shkolnikov V.M., McKee M. (2009). Alcohol and Russian mortality: a continuing crisis. Addiction, 104(10), 1630-1636. DOI: https://doi.org/10.1111/j.13600443.2009.02655.x.

Loader B.D. (1998). Cyberspace Divide: Equality, Agency and Policy in the Information Society. Routledge, London.

Lopez A., Collishaw N., Piha T. (1994). A descriptive model of the cigarette epidemic in developed countries. Tobacco Control, 3(3), 242-247.

Oksuzyan A., Juel K., Vaupel J.W., Christensen K. (2008). Men: good health and high mortality. Sex differences in health and aging. Aging clinical and experimental research, 20(2), 91102. DOI: https://doi.org/10.1007/BF03324754 (данные загружены 10.08.20).

Pampel F.C. (2005). Diffusion, cohort change, and social patterns of smoking. Social Science Research, 34(1), 117-139.

Sargan J.D. (1958). The estimation of economic relationships using instrumental variables. Econometrica, 26, 393-415. 
Stock J.H., Yogo M. (2005). Testing for weak instruments in linear IV regression. In Andrews D.W.K., Stock J.H. (Eds.), Identification and Inference for Econometric Models: Essays in Honor of Thomas Rothenberg (pp. 80-108). New York: Cambridge University Press.

Swartz L.H.G., Noell J.W., Schroeder S.W., Ary D.V. (2006). A randomised control study of a fully automated internet based smoking cessation programme. Tobacco Control, 15(1), 7-12.

Tavares A.I. (2020). Self-assessed health among older people in Europe and internet use. International journal of medical informatics, 141, 104240. Advance online publication. DOI: https://doi.org/10.1016/j.ijmedinf.2020.104240 (данные загружены 10.08.20).

Thun M., Peto R., Boreham J., Lopez A. (2012). Stages of the cigarette epidemic on entering its second century. Tobacco Control, 21(2), 96-101. 


\section{ПРИЛОЖЕНИЯ}

\section{Приложение 1. Описание переменных, использованных в работе}

\section{Таблица П1.1. Описание переменных, использованных в работе}

\begin{tabular}{|c|c|}
\hline Название & Описание \\
\hline Здоровье & Самооценка здоровья: от 1 - очень плохое, до 5 - очень хорошее \\
\hline Хорошее здоровье & $\begin{array}{l}\text { Хорошее здоровье: } 1 \text { - если респондент указывает его как «хорошее» или } \\
\text { «очень хорошее», } 0 \text { - иначе }\end{array}$ \\
\hline Курение & $\begin{array}{l}\text { Объём курения: от } 1 \text { - не курит и не курил, до } 7 \text { - выкуривает более } 1 \text { пачки } \\
\text { в день }\end{array}$ \\
\hline Алкоголь & Пьёт ли респондент алкоголь: 1 - да, 0 - нет \\
\hline Водка & $\begin{array}{l}\text { Объём потребления водки: от } 1 \text { - не употребляет, до } 6 \text { - употребляет } \\
\text { практически каждый день }\end{array}$ \\
\hline Вино & $\begin{array}{l}\text { Объём потребления вина: от } 1 \text { - не употребляет, до } 6 \text { - употребляет } \\
\text { практически каждый день }\end{array}$ \\
\hline Пиво & $\begin{array}{l}\text { Объём потребления пива: от } 1 \text { - не употребляет, до } 6 \text { - употребляет } \\
\text { практически каждый день }\end{array}$ \\
\hline Мужчина & Пол: 1 - если респондент мужского пола, 0 - если женского \\
\hline Интернет & $\begin{array}{l}\text { Частота выхода в Интернет: от } 1 \text { - не пользуюсь, до } 4 \text { - каждый день или } \\
\text { почти каждый день }\end{array}$ \\
\hline Уровень образования & $\begin{array}{l}\text { Уровень образования: от } 1 \text { - не имеет основного общего, до } 9 \text { - кадр высшей } \\
\text { квалификации (аспирантура и выше) }\end{array}$ \\
\hline Возраст & Возраст, лет \\
\hline Возраст ${ }^{\wedge}$ & Квадрат возраста \\
\hline Женат или замужем & $\begin{array}{l}\text { Семейное положение: } 1 \text { - состоит в зарегистрированном или } \\
\text { незарегистрированном браке, } 0 \text { - в браке не состоит }\end{array}$ \\
\hline Логарифм дохода & Логарифм дохода на члена домохозяйства \\
\hline Город & Местность проживания: 1 - городская, 0 - сельская \\
\hline Число детей & Число детей в домохозяйстве \\
\hline Есть дети & Индикаторная переменная наличия детей в домохозяйстве ( 1 - есть, 0 - нет) \\
\hline Занятый & $\begin{array}{l}\text { Индикаторная переменная статуса на рынке труда: (1 - занятые в экономике } \\
\text { (работающие), } 0 \text { - иначе) }\end{array}$ \\
\hline Региональные эффекты & Индикаторные переменные регионов \\
\hline
\end{tabular}


Приложение 2. Таблицы с результатами регрессионного анализа о влиянии Интернета на табакокурение и потребление алкоголя

Таблица П2.1. Тобит-модели влияния частоты пользования Интернетом на объёмы курения курящими индивидами

\begin{tabular}{|c|c|c|c|c|}
\hline Переменные & $\begin{array}{l}\text { Модель } 5 \text { тобит } \\
\text { (мужчины) }\end{array}$ & $\begin{array}{l}\text { Модель } 6 \text { тобит } \\
\text { (мужчины) }\end{array}$ & $\begin{array}{c}\text { Модель } 7 \text { тобит } \\
\text { (женщины) }\end{array}$ & $\begin{array}{l}\text { Модель } 8 \text { тобит } \\
\text { (женщины) }\end{array}$ \\
\hline$\Delta$ Интернет & $-0,0514 *$ & $-0,0570^{*}$ & $0,125 * * *$ & $0,0982 * *$ \\
\hline АУровень образования & $-0,220 * * *$ & $-0,233^{* * *}$ & $-0,238^{* * *}$ & $-0,247 * * *$ \\
\hline$\Delta$ Женат или замужем & $\begin{array}{c}(0,0127) \\
0,0563 \\
(0,0633)\end{array}$ & $\begin{array}{c}(0,0126) \\
0,0564 \\
(0,0633)\end{array}$ & $\begin{array}{c}(0,0191) \\
-0,365 * * * \\
(0,0809)\end{array}$ & $\begin{array}{c}(0,0192) \\
-0,332 * * * \\
(0,0825)\end{array}$ \\
\hline АЛогарифм дохода & $\begin{array}{c}-0,149 * * * \\
(0,0549)\end{array}$ & $\begin{array}{c}-0,125^{* *} \\
(0,0544)\end{array}$ & $\begin{array}{l}-0,170 * * \\
(0,0811)\end{array}$ & $\begin{array}{c}-0,104 \\
(0,0817)\end{array}$ \\
\hline$\Delta$ Город & $\begin{array}{l}-0,0493 \\
(0,0718)\end{array}$ & $\begin{array}{l}-0,0277 \\
(0,0720)\end{array}$ & $\begin{array}{l}0,0769 \\
(0,109)\end{array}$ & $\begin{array}{c}0,127 \\
(0,106)\end{array}$ \\
\hline$\Delta$ Число детей & $\begin{array}{l}-0,0377 \\
(0,0345)\end{array}$ & $\begin{array}{l}-0,0244 \\
(0,0343)\end{array}$ & $\begin{array}{l}-0,0360 \\
(0,0508)\end{array}$ & $\begin{array}{c}0,00721 \\
(0,0497)\end{array}$ \\
\hline$\Delta$ Занятый & $\begin{array}{c}0,717 * * * \\
(0,0642)\end{array}$ & $\begin{array}{c}0,715^{* * *} * \\
(0,0645)\end{array}$ & $\begin{array}{c}0,548 * * * \\
(0,0869)\end{array}$ & $\begin{array}{c}0,589 * * * \\
(0,0874)\end{array}$ \\
\hline Возраст & $\begin{array}{c}0,256 * * * \\
(0,0163)\end{array}$ & $\begin{array}{c}0,257 * * * \\
(0,0163)\end{array}$ & $\begin{array}{c}0,235 * * * \\
(0,0264)\end{array}$ & $\begin{array}{c}0,220 * * * \\
(0,0266)\end{array}$ \\
\hline Возраст $^{\wedge 2}$ & $\begin{array}{c}-0,00288^{* * *} \\
(0,000187)\end{array}$ & $\begin{array}{c}-0,00289 * * * * \\
(0,000187)\end{array}$ & $\begin{array}{c}-0,00327 * * * \\
(0,000311)\end{array}$ & $\begin{array}{c}-0,00310^{* * * *} \\
(0,000314)\end{array}$ \\
\hline Константа & $\begin{array}{c}-5,000 * * * \\
(0,781)\end{array}$ & $\begin{array}{c}-5,299 * * * \\
(0,339)\end{array}$ & $\begin{array}{c}-5,719 * * * \\
(0,903)\end{array}$ & $\begin{array}{c}-7,733 * * * \\
(0,542)\end{array}$ \\
\hline $\begin{array}{l}\text { Региональные эффекты } \\
\text { Число наблюдений }\end{array}$ & $\begin{array}{c}\text { Есть } \\
15,387\end{array}$ & $\begin{array}{c}\text { Нет } \\
15,387\end{array}$ & $\begin{array}{c}\text { Есть } \\
21,351\end{array}$ & $\begin{array}{c}\text { Нет } \\
21,351\end{array}$ \\
\hline
\end{tabular}

Источник: Построено авторами в программном пакете Stata 14.2.

Примечание: Зависимая переменная: первая разность потребления табачной продукиии, в табличе указаны коэффициенты моделей.

Здесь и далее знаком А отмечены переменные, взятые в первых разностях.

Значимость: $*-10 \%, * *-5 \%, * * *-1 \%$. 
Таблица П2.2. Тобит-модели влияния частоты пользования Интернетом на объёмы потребления вина пьющими индивидами

\begin{tabular}{|c|c|c|c|c|}
\hline Переменные & $\begin{array}{c}\text { Модель } 9 \text { тобит } \\
\text { (мужчины) }\end{array}$ & $\begin{array}{c}\text { Модель } 10 \text { тобит } \\
\text { (мужчины) }\end{array}$ & $\begin{array}{c}\text { Модель } 11 \text { тобит } \\
\text { (женщины) }\end{array}$ & $\begin{array}{c}\text { Модель } 12 \text { тобит } \\
\text { (женщины) }\end{array}$ \\
\hline \multirow[t]{2}{*}{ АИнтернет } & $0,185^{* * *}$ & $0,173 * * *$ & $0,111 * * *$ & $0,0913 * *$ \\
\hline & $(0,00750)$ & $(0,0544)$ & $(0,0384)$ & $(0,0381)$ \\
\hline \multirow[t]{2}{*}{$\Delta$ Уровень образования } & $0,0220 * * *$ & 0,0204 & $0,0329 * *$ & $0,0306^{*}$ \\
\hline & $(0,00212)$ & $(0,0234)$ & $(0,0157)$ & $(0,0159)$ \\
\hline \multirow[t]{2}{*}{ 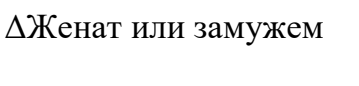 } & $-0,208 * * *$ & $-0,212^{*}$ & $-0,149 * *$ & $-0,143 * *$ \\
\hline & $(0,00828)$ & $(0,121)$ & $(0,0617)$ & $(0,0635)$ \\
\hline \multirow[t]{2}{*}{$\Delta$ Логарифм дохода } & $0,121 * * *$ & 0,121 & $0,287 * * *$ & $0,306 * * *$ \\
\hline & $(0,0179)$ & $(0,104)$ & $(0,0668)$ & $(0,0669)$ \\
\hline \multirow[t]{2}{*}{$\Delta$ Город } & $0,0765 * * *$ & $-0,0938$ & 0,00332 & $-0,00161$ \\
\hline & $(0,0140)$ & $(0,138)$ & $(0,0954)$ & $(0,0921)$ \\
\hline \multirow[t]{2}{*}{$\Delta$ Число детей } & $-0,0772 * * *$ & $-0,0591$ & 0,0424 & 0,0381 \\
\hline & $(0,00889)$ & $(0,0659)$ & $(0,0414)$ & $(0,0415)$ \\
\hline \multirow[t]{2}{*}{$\Delta$ Занятый } & $-0,168 * * *$ & $-0,161$ & $-0,211 * * *$ & $-0,184 * *$ \\
\hline & $(0,0104)$ & $(0,131)$ & $(0,0752)$ & $(0,0752)$ \\
\hline \multirow[t]{2}{*}{ Возраст } & $0,0881 * * *$ & $0,0860 * * *$ & $0,0589 * * *$ & $0,0472 * *$ \\
\hline & $(0,000851)$ & $(0,0332)$ & $(0,0224)$ & $(0,0227)$ \\
\hline \multirow[t]{2}{*}{ Возраст $^{\wedge 2}$} & $-0,00106 * * *$ & $-0,00103 * * *$ & $-0,000880 * * *$ & $-0,000764 * * *$ \\
\hline & $\left(1,43 * 10^{-5}\right)$ & $(0,000372)$ & $(0,000256)$ & $(0,000260)$ \\
\hline \multirow[t]{2}{*}{ Константа } & $-17,77 * * *$ & $-4,968 * * *$ & $-2,771 * * *$ & $-2,551 * * *$ \\
\hline & $(0,0372)$ & $(0,720)$ & $(0,895)$ & $(0,479)$ \\
\hline Региональные эффекты & Есть & Нет & Есть & Нет \\
\hline Число наблюдений & 8,077 & 8,077 & 9,357 & 9,357 \\
\hline
\end{tabular}

Источник: Построено авторами в программном пакете Stata 14.2.

Примечание: Зависимая переменная: первая разность потребления вина, в таблице указань коэффициенты моделей.

Значимость: $*-10 \%, * *-5 \%, * * *-1 \%$. 
Таблица П2.3. Тобит-модели влияния частоты пользования Интернетом на объёмы потребления пива пьющими индивидами

\begin{tabular}{|c|c|c|c|c|}
\hline Переменные & $\begin{array}{c}\text { Модель } 13 \text { тобит } \\
\text { (мужчины) }\end{array}$ & $\begin{array}{c}\text { Модель } 14 \text { тобит } \\
\text { (мужчины) }\end{array}$ & $\begin{array}{c}\text { Модель } 15 \text { тобит } \\
\text { (женщины) }\end{array}$ & $\begin{array}{c}\text { Модель } 16 \text { тобит } \\
\text { (женщины) }\end{array}$ \\
\hline \multirow[t]{2}{*}{ АИнтернет } & 0,0393 & 0,0355 & 0,163 *** & $0,138 * * *$ \\
\hline & $(0,0262)$ & $(0,0260)$ & $(0,0379)$ & $(0,0382)$ \\
\hline \multirow[t]{2}{*}{$\Delta$ Уровень образования } & $-0,106 * * *$ & $-0,108 * * *$ & $-0,114 * * *$ & $-0,113 * * *$ \\
\hline & $(0,0111)$ & $(0,0111)$ & $(0,0150)$ & $(0,0152)$ \\
\hline \multirow[t]{2}{*}{ 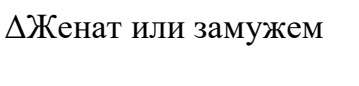 } & $-0,0817$ & $-0,0709$ & $0,124 * *$ & $0,108^{*}$ \\
\hline & $(0,0553)$ & $(0,0557)$ & $(0,0620)$ & $(0,0629)$ \\
\hline \multirow[t]{2}{*}{$\Delta$ Логарифм дохода } & $-0,00430$ & $-0,00260$ & $-0,0691$ & $-0,0421$ \\
\hline & $(0,0474)$ & $(0,0470)$ & $(0,0638)$ & $(0,0632)$ \\
\hline \multirow[t]{2}{*}{$\Delta$ Город } & $-0,0594$ & $-0,0687$ & $-0,108$ & $-0,116$ \\
\hline & $(0,0641)$ & $(0,0619)$ & $(0,0869)$ & $(0,0855)$ \\
\hline \multirow[t]{2}{*}{$\Delta$ Число детей } & $0,0922 * * *$ & $0,0809 * * *$ & $-0,0313$ & $-0,0190$ \\
\hline & $(0,0304)$ & $(0,0300)$ & $(0,0414)$ & $(0,0415)$ \\
\hline \multirow[t]{2}{*}{$\Delta$ Занятый } & $0,354 * * *$ & $0,369 * * *$ & $0,242 * * *$ & $0,256^{* * *}$ \\
\hline & $(0,0583)$ & $(0,0579)$ & $(0,0719)$ & $(0,0726)$ \\
\hline \multirow[t]{2}{*}{ Возраст } & $0,0420 * * *$ & $0,0452 * * *$ & $-0,00325$ & $-0,00999$ \\
\hline & $(0,0152)$ & $(0,0153)$ & $(0,0213)$ & $(0,0217)$ \\
\hline \multirow[t]{2}{*}{ Возраст $^{\wedge}$} & $-0,000664 * * *$ & $-0,000693 * * *$ & $-0,000422 *$ & $-0,000353$ \\
\hline & $(0,000172)$ & $(0,000173)$ & $(0,000248)$ & $(0,000253)$ \\
\hline \multirow[t]{2}{*}{ Константа } & $-0,851$ & $-0,423$ & $-0,209$ & $-0,533$ \\
\hline & $(0,643)$ & $(0,320)$ & $(0,827)$ & $(0,445)$ \\
\hline Региональные эффекты & Есть & Нет & Есть & Нет \\
\hline Число наблюдений & 8,077 & 8,077 & 9,357 & 9,357 \\
\hline
\end{tabular}

Источник: Построено авторами в программном пакете Stata 14.2.

Примечание: Зависимая переменная: первая разность потребления пива, в таблице указань коэффициенты моделей

Значимость: $*-10 \%, * *-5 \%, * * *-1 \%$. 
Таблица П2.4. Тобит-модели влияния частоты пользования Интернетом на объёмы потребления водки пьющими индивидами

\begin{tabular}{|c|c|c|c|c|}
\hline Переменные & $\begin{array}{c}\text { Модель } 17 \text { тобит } \\
\text { (мужчины) }\end{array}$ & $\begin{array}{c}\text { Модель } 18 \text { тобит } \\
\text { (мужчины) }\end{array}$ & $\begin{array}{c}\text { Модель } 19 \text { тобит } \\
\text { (женщины) }\end{array}$ & $\begin{array}{c}\text { Модель } 20 \text { тобит } \\
\text { (женщины) }\end{array}$ \\
\hline \multirow[t]{2}{*}{$\Delta$ Интернет } & $-0,132 * * *$ & $-0,0874 * * *$ & 0,0275 & $-0,0130$ \\
\hline & $(0,0312)$ & $(0,0311)$ & $(0,0607)$ & $(0,0609)$ \\
\hline \multirow[t]{2}{*}{$\Delta$ Уровень образования } & $-0,0846 * * *$ & $-0,0874 * * *$ & $-0,101 * * *$ & $-0,105 * * *$ \\
\hline & $(0,0128)$ & $(0,0128)$ & $(0,0255)$ & $(0,0263)$ \\
\hline \multirow[t]{2}{*}{ 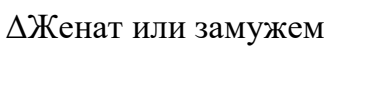 } & 0,0362 & 0,0250 & 0,0536 & 0,0769 \\
\hline & $(0,0657)$ & $(0,0668)$ & $(0,105)$ & $(0,109)$ \\
\hline \multirow[t]{2}{*}{$\Delta$ Логарифм дохода } & $0,0998 *$ & $0,130 * *$ & 0,0894 & 0,0997 \\
\hline & $(0,0580)$ & $(0,0573)$ & $(0,114)$ & $(0,116)$ \\
\hline \multirow[t]{2}{*}{$\Delta$ Город } & $-0,00467$ & 0,00267 & $-0,425 * * *$ & $-0,338 * *$ \\
\hline & $(0,0750)$ & $(0,0748)$ & $(0,160)$ & $(0,150)$ \\
\hline \multirow[t]{2}{*}{$\Delta$ Число детей } & $-0,0246$ & $-0,0159$ & $-0,0955$ & $-0,0914$ \\
\hline & $(0,0347)$ & $(0,0353)$ & $(0,0697)$ & $(0,0734)$ \\
\hline \multirow[t]{2}{*}{$\Delta$ Занятый } & $0,187 * * *$ & $0,194 * * *$ & 0,0901 & 0,153 \\
\hline & $(0,0687)$ & $(0,0694)$ & $(0,123)$ & $(0,126)$ \\
\hline \multirow[t]{2}{*}{ Возраст } & $0,107 * * *$ & $0,102 * * *$ & $0,127 * * *$ & $0,106 * * *$ \\
\hline & $(0,0181)$ & $(0,0184)$ & $(0,0357)$ & $(0,0369)$ \\
\hline \multirow[t]{2}{*}{ Возраст $^{\wedge}$} & $-0,000959 * * *$ & $-0,000900 * * *$ & $-0,00120 * * *$ & $-0,000968 * *$ \\
\hline & $(0,000199)$ & $(0,000202)$ & $(0,000390)$ & $(0,000403)$ \\
\hline \multirow[t]{2}{*}{ Константа } & $-2,963 * * *$ & $-3,492 * * *$ & $-5,848 * * *$ & $-6,486 * * *$ \\
\hline & $(0,668)$ & $(0,401)$ & $(1,235)$ & $(0,820)$ \\
\hline Региональные эффекты & Есть & Нет & Есть & Нет \\
\hline Число наблюдений & 8,077 & 8,077 & 9,357 & 9,357 \\
\hline
\end{tabular}

Источник: Построено авторами в программном пакете Stata 14.2.

Примечание: Зависимая переменная: первая разность потребления водки, в таблице указаны коэффициенты моделей.

Значимость: $*-10 \%, * *-5 \%, * * *-1 \%$. 
Таблица П2.5. Тобит-модели влияния частоты пользования Интернетом на объёмы курения курящими индивидами (с индикатором наличия детей)

\begin{tabular}{|c|c|c|c|c|}
\hline Переменные & $\begin{array}{c}\text { Модель } 21 \text { тобит } \\
\text { (мужчины) }\end{array}$ & $\begin{array}{c}\text { Модель } 22 \text { тобит } \\
\text { (мужчины) }\end{array}$ & $\begin{array}{c}\text { Модель } 23 \text { тобит } \\
\text { (женщины) }\end{array}$ & $\begin{array}{c}\text { Модель } 24 \text { тобит } \\
\text { (женщины) }\end{array}$ \\
\hline \multirow[t]{2}{*}{ АИнтернет } & $-0,0508 * *$ & $-0,0532 * *$ & $0,122 * * *$ & $0,0843 * *$ \\
\hline & $(0,0216)$ & $(0,0216)$ & $(0,0328)$ & $(0,0329)$ \\
\hline \multirow[t]{2}{*}{$\Delta$ Уровень образования } & $-0,240 * * *$ & $-0,248 * * *$ & $-0,265 * * *$ & $-0,269 * * *$ \\
\hline & $(0,0099)$ & $(0,0099)$ & $(0,0147)$ & $(0,0149)$ \\
\hline \multirow[t]{2}{*}{ 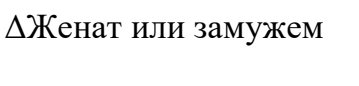 } & $0,0894 * *$ & $0,0907 * *$ & $-0,349 * * *$ & $-0,329 * * *$ \\
\hline & $(0,0443)$ & $(0,0445)$ & $(0,0559)$ & $(0,0566)$ \\
\hline \multirow[t]{2}{*}{$\Delta$ Логарифм дохода } & $-0,159 * * *$ & $-0,130 * * *$ & $-0,053$ & 0,018 \\
\hline & $(0,0367)$ & $(0,0359)$ & $(0,0536)$ & $(0,0530)$ \\
\hline \multirow[t]{2}{*}{$\Delta$ Город } & $-0,0457$ & $-0,0336$ & 0,2563 & $0,251 * * *$ \\
\hline & $(0,0482)$ & $(0,0480)$ & $(0,073)$ & $(0,072)$ \\
\hline \multirow[t]{2}{*}{ Есть дети } & $-0,250 * * *$ & $-0,257 * * *$ & $-0,159 * * *$ & $-0,164 * * *$ \\
\hline & $(0,0430)$ & $(0,0430)$ & $(0,0612)$ & $(0,0619)$ \\
\hline \multirow[t]{2}{*}{$\Delta$ Занятый } & $0,747 * * *$ & $0,745^{* * *}$ & $0,567 * * *$ & $0,608 * * *$ \\
\hline & $(0,0476)$ & $(0,0477)$ & $(0,0644)$ & $(0,0648)$ \\
\hline \multirow[t]{2}{*}{ Возраст } & $0,249 * * *$ & $0,251 * * *$ & $0,249 * * *$ & $0,238 * * *$ \\
\hline & $(0,0124)$ & $(0,0125)$ & $(0,0199)$ & $(0,0201)$ \\
\hline \multirow[t]{2}{*}{ Возраст $^{\wedge}$} & $-0,00287 * * *$ & $-0,00289 * * *$ & $-0,00345 * * *$ & $-0,00334 * * *$ \\
\hline & $(0,000142)$ & $(0,000142)$ & $(0,000235)$ & $(0,000237)$ \\
\hline \multirow[t]{2}{*}{ Константа } & $-4,507 * * *$ & $-4,993 * * *$ & $-6,693 * * *$ & $-7,861 * * *$ \\
\hline & $(0,530)$ & $(0,262)$ & $(0,705)$ & $(0,422)$ \\
\hline Региональные эффекты & Есть & Нет & Есть & Нет \\
\hline Число наблюдений & 27,056 & 27,056 & 37,955 & 37,955 \\
\hline
\end{tabular}

Источник: Построено авторами в программном пакете Stata 14.2.

Примечание: Зависимая переменная: первая разность потребления табачной продукции, в таблице указаны коэффициенты моделей

Значимость: $*-10 \%, * *-5 \%, * * *-1 \%$. 


\section{Приложение 3. Тесты на релевантность и экзогенность инструментальной переменной «частота общения в Интернете» в модели оценки состояния здоровья}

Тестирование на релевантность. Для тестирования инструмента на релевантность воспользуемся тестом на слабые инструменты (Stock, Yogo 2005). На первом шаге строится регрессия, зависимой переменной в которой выступает частота пользования Интернетом, а объясняющими переменными - частота общения в Интернете (рассматриваемая как ключевой инструмент) и остальные контрольные переменные, участвующие в уравнениях обоих шагов (возраст, доход, город/село, уровень образования, семейное положение, число детей, статус на рынке труда, а также регионы - в моделях с региональными эффектами). Далее оценивается F-значение регрессии частоты использования Интернета на частоту пользования Интернетом и по «правилу большого пальца» расчётное значение F-статистики сравнивается с 10. Если F-значение превосходит 10, инструмент полагается релевантным.

К сожалению, из-за технической ошибки пакет Stata не обрабатывал запрос на построение соответствующих F-статистик, поэтому при проверке релевантности инструмента мы опирались на то, что частота общения в Интернете выступает единственным регрессором, и в таком случае F-расчётное значение, говорящее нам о значимости уравнения, представляет собой квадрат t-расчётного значения коэффициента при регрессоре - см. напр., (Магнус, Катышев, Пересецкий 2004). В таком случае нам достаточно того результата, что t-расчётные значения во всех четырех случаях строго превышают 10, что говорит о том, что во всех случаях наш инструмент заведомо релевантен (таблица П2.5).

Таблица П3.1. Результаты тестирования инструмента на релевантность

\begin{tabular}{l|c|c|c|c}
\hline & $\begin{array}{c}\text { Модель 1 } \\
\text { Женщины, без } \\
\text { региональных } \\
\text { эффектов }\end{array}$ & $\begin{array}{c}\text { Модель 2 } \\
\text { Мужчины, без } \\
\text { региональных } \\
\text { эффектов }\end{array}$ & $\begin{array}{c}\text { Модель 3 } \\
\text { Женщины, с } \\
\text { региональными } \\
\text { эффектами }\end{array}$ & $\begin{array}{c}\text { Модель 4 } \\
\text { Мужчины, с } \\
\text { региональными } \\
\text { эффектами }\end{array}$ \\
\hline t-расчётное значение & 247,50 & 182,78 & 245,76 & 181,68 \\
\hline
\end{tabular}

Источник: Рассчитано авторами в программном пакете Stata 14.2.

Тестирование на экзогенность. В силу того, что в модели задействовано равное количество (по 1) инструментов и инструментируемых переменных (переменных, положенных эндогенными), статистики хи-квадрат не имеют степеней свобод, что лишает нас возможности прямого проведения теста Саргана для тестирования экзогенности инструмента. Для обхода технического ограничения теста мы включаем в модель дополнительный инструмент - лаг переменной образования. Таким образом, у нас появляется возможность рассчитать статистики хи-квадрат с одной степенью свободы, что даёт нам возможность получить представление об экзогенности инструмента. Во всех моделях (таблица П3.2). Р-значение теста Саргана превосходит 0,1, что говорит о том, что на всех уровнях значимости инструменты совместно экзогенны. Из этого следует и частный результат - об экзогенности по построению частоты общения в Интернете по отношению к самооценке здоровья. 
Таблица П3.2. Результаты тестирования инструмента на экзогенность

\begin{tabular}{c|c|c|c|c}
\hline & $\begin{array}{c}\text { Модель 1 } \\
\text { Женщины, без } \\
\text { региональных } \\
\text { эффектов }\end{array}$ & $\begin{array}{c}\text { Модель 2 } \\
\text { Мужчины, без } \\
\text { региональных } \\
\text { эффектов }\end{array}$ & $\begin{array}{c}\text { Модель 3 } \\
\text { Женщины, с } \\
\text { региональными } \\
\text { эффектами }\end{array}$ & $\begin{array}{c}\text { Модель 4 } \\
\text { Мужчины, с } \\
\text { региональными } \\
\text { эффектами }\end{array}$ \\
\hline Р-значение теста Саргана & 0,3216 & 0,2875 & 0,4209 & 0,3069 \\
\hline
\end{tabular}

Источник: Рассчитано авторами в программном пакете Stata 14.2. 


\title{
IS THE INTERNET A HEALTH-PRESERVING FACTOR IN RUSSIA?
}

\author{
IRINA KALABIKHINA, ANTON KOLOTUSHA
}

\begin{abstract}
With the growing popularity of the Internet in Russia, it is important to find out how the frequency of Internet use affects people's health and self-preservation behavior. We test the following optimistic hypotheses: other things being equal, relatively frequent Internet use corresponds to better health and less consumption of alcohol and tobacco products. Using data from the last 3 waves (2014, 2016, 2018) of the Comprehensive Survey of Living Conditions of the Population (CSLC), we build binary probit models using instrumental variables to determine the impact of the Internet on health and first-difference tobit models to assess the impact of the Internet on the volume of consumption of alcohol and tobacco products. The first group of models demonstrates a significant positive impact of the Internet on health for both genders. In other models, the hypotheses of our analysis are partially confirmed: with an increase in the frequency of Internet use, men smoke and drink less, and prefer low-alcohol beverages more, but in the female sample, the result does not confirm the hypothesis of a positive impact of the Internet on reducing tobacco and alcohol consumption. We believe that this result is explained by both the quality of data and the current stage of women's emancipation in Russia. In addition, unlike for men, for women the Internet is not a substitute for leisure time spent drinking vodka.
\end{abstract}

Our general conclusion is that in order to preserve and increase the health capital of Russian residents, it is necessary to expand the opportunities for using the Internet.

Key words: Internet, health, self-preserving behavior, tobit models, binary probit models, alcohol, smoking.

IRINA KALABIKHINA (ikalabikhina@yandex.ru), LoMonosov Moscow STATE UNIVERSITY, RuSSIA.

Anton Kolotusha (tony_kol@mail.ru), Lomonosov Moscow STATE University, Russia.

THE MANUSCRIPT WAS PREPARED WITH THE FINANCIAL SUPPORT OF THE FACULTY OF ECONOMICS OF LOMONOSOV MOSCOW STATE UNIVERSITY AS PART OF A RESEARCH PROJECT ON «POPULATION REPRODUCTION IN A DIGITAL SOCIETY».

DATE RECEIVED : JUNE 2020.

\section{REFERENCES}

Antonov A.I. (1989). Opyt issledovaniya ustanovok na zdorov'ye i prodolzhitel'nost' zhizni. Sotsial'nyye problemy zdorov'ya i prodolzhitel'nosti zhizni, 44. Moscow. (In Russ.)

Barnighausen T., Chaiyachati K., Chimbindi N., Peoples A., Haberer J., Newell M.L. (2011). Interventions to increase antiretroviral adherence in sub-Saharan Africa: A systematic review of evaluation studies. Lancet Infect. Dis., 11, 942-951

Bauer T., Göhlmann S., Sinning M. (2007). Gender differences in smoking behavior. Health Economics, 16(9), 895-909.

Bessière K., Pressman S., Kiesler S., Kraut R. (2010). Effects of internet use on health and depression: a longitudinal study. Journal of medical Internet research, 12(1). DOI: https://doi.org/10.2196/jmir.1149 (data downloaded on 10.08.20).

Borisov V. (1999). Demografiya [Demography], Moskva, Izdatel'skiy dom «Nota Bene». (In Russ.) 
Boytsov S.A., Samorodskaya I.V., Semenov V.YU. (2016). Role of medical and non-medical factors in mortality rate: alcohol. Social and Clinical Psychiatry, 26(2), 97-106. (In Russ.)

Bundorf M.K., Wagner T.H., Singer S.J., Baker L.C. (2006). Who searches the internet for health information? Health Services Research, 41(3), 819-836.

Cesare N., Lee H., McCormick T., Spiro E., Zagheni E. (2018). Promises and pitfalls of using digital traces for demographic research. Demography, 55(5), 1979-1999.

Choun K., Achanta S., Naik B., Tripathy J.P., Thai S., Lorent N., Khun K.E., Griensven J.V., Kumar A.M.V.,

Zachariah R. (2017). Using mobile phones to ensure that referred tuberculosis patients reach their treatment facilities: A call that makes a difference. Health Serv. Res., 17, 575.

Demyanova A.A. (2005). Factors and Types of Alcohol and Tobacco Consumption in Russia. Economic Sociology, 6(1), 78-94. (In Russ.)

DiMaggio P., Hargittai E., Neuman W.R., Robinson, J. P. (2001). Social Implications of the Internet. Annual Review of Sociology, 27(1), 307-336.

Edinaya mezhvedomstvennaya informatsionno-statisticheskaya sistema (EMISS) (2020). Dolya naseleniya, yavlyayushchikhsya aktivnymi pol'zovatelyami seti Internet, $v$ obshchey chislennosti naseleniya RF (2020) [Share of population, who are active users of Internet, in total population of Russian Federation]. (In Russ.) Retrieved from https://www.fedstat.ru/indicator/43566 (data retrieved 02.05.2020).

Federal State Statistic Service (Rosstat). (2014). Comprehensive survey of living conditions of the population. 2014. (In Russ.)

Federal State Statistic Service (Rosstat). (2016). Comprehensive survey of living conditions of the population. 2016. (In Russ.)

Federal State Statistic Service (Rosstat). (2018). Comprehensive survey of living conditions of the population. 2018. (In Russ.)

Feil E.G., Noell J., Lichtenstein E., Boles S.M., McKay H.G. (2003). Evaluation of an Internetbased smoking cessation program: Lessons learned from a pilot study. Nicotine \& Tobacco Research, 5(2), 189-194.

Grøtvedt L., Stavem K. (2005). Association between age, gender and reasons for smoking cessation. Scandinavian Journal of Public Health, 33(1), 72-76.

Gruzdeva M. (2017). Instrumenty formirovaniya samosokhranitel'nykh praktik naseleniya: sotsial'nyye seti i blogosfera. Sotsial'noye prostranstvo, 4(11), 5. (In Russ.)

June K.J., Sohn S.Y., So A.Y., Yi G.M., Park S.H. (2007). A study of factors that influence Internet addiction, smoking, and drinking in high school students. Taehan Kanho Hakhoe chi, 37(6), 872-882.

Kahn T. (2004). Mobile Phones Keep Track of HIV Treatments. URL: http://www.scidev.net/global/health/news/mobile-phones-keep-track-of-hiv-treatments.html (data downloaded on 10.08.20).

Kalabikhina I., Matyushina D. (2018). A study of the population's attitude to telemedicine technologies on the example of online medical consultations. Population and Economics, ARPHA Platform, 2(2), 78-109.

Kalabikhina I.E. (2019). Demographic reflections on the digital economy. Vestnik Moskovskogo Universiteta [Moscow University Bulletin], 6(6), 147-166. (In Russ.) 
Kalabikhina I.E., Kuznetsova P.O. (2019). Gender aspects of tobacco epidemic in Russia. Journal of New Economic Association, 44(4), 161-187. (In Russ.)

Kalabugina E.A. (2013). Vliyaniye elektronnykh sredstv na zdorov'ye studentov. Vestnik YUzhno-Ural'skogo gosudarstvennogo universiteta. Seriya: Obrazovaniye. Pedagogicheskiye nauki, 5(2), 67-73. (In Russ.)

Killian T.S. (2012). Health-information seeking on the Internet and current smoking status: Evidence from the national health interview survey. Open Journal of Preventive Medicine, 2(3), 291-298.

Kling R. (2000). Learning about information technologies and social change: The contribution of social informatics. Information Society, 16(3), 217-232.

Kuz'mich O., Roshchin S. (2008). Is it really better to be healthy? Economic returns on healthcare in Russia. HSE Economic Journal, 12(1), 29-55. (In Russ.)

Leon D.A., Shkolnikov V.M., McKee M. (2009). Alcohol and Russian mortality: a continuing crisis. Addiction, 104(10), 1630-1636. DOI: https://doi.org/10.1111/j.13600443.2009.02655.x.

Loader B.D. (1998). Cyberspace Divide: Equality, Agency and Policy in the Information Society. Routledge, London.

Lopez A., Collishaw N., Piha T. (1994). A descriptive model of the cigarette epidemic in developed countries. Tobacco Control, 3(3), 242-247.

Lyashok V.YU., Roshchin S.YU. (2015). Effect on health on labor supply of elderly. Applied Econometrics, 4 (40), 6-27. (In Russ.)

Magnus YA.R., Katyshev P.K., Peresetskiy A.A. (2004). Ekonometrika [Econometrics]. Nachal'nyy kurs: ucheb. 6-e izd., pererab. i dop. Moscow: Delo. 576 s. (In Russ.)

Medkov V. (2002). Demografiya: uchebnoye posobiye [Demography: tutorial]. Seriya "Uchebniki i uchebnyye posobiya," Rostov-na-Donu, Feniks. (In Russ.)

Nazarov V.S., Dormidontova YU.A., Lyashok V.YU. (2014). Analysis of the factors that influence workers' decision to retire. Journal of New Economic Association, 4, 66-86. (In Russ.)

Nemtsov A.V. (2014). Alkogol'naya situatsiya v Rossii. Sobriologiya, 2(2), 13-19. (In Russ.)

Oksuzyan A., Juel K., Vaupel J.W., Christensen K. (2008). Men: good health and high mortality. Sex differences in health and aging. Aging clinical and experimental research, 20(2), 91102. DOI: https://doi.org/10.1007/BF03324754 (data downloaded on 10.08.20).

Pampel F.C. (2005). Diffusion, cohort change, and social patterns of smoking. Social Science Research, 34(1), 117-139.

Radayev V.V. (2020). Millenials: How the Russian Society Changes [Text]. HSE Publishing House, 2nd edition, Moscow, 224 s. (In Russ.)

Revyakin E. (2006). Samosokhranitel'noye povedeniye: ponyatiye i sushchnost'. Vestnik IG.EU, 1, 1-4. (In Russ.)

Sargan J.D. (1958). The estimation of economic relationships using instrumental variables. Econometrica, 26, 393-415.

Stock J.H., Yogo M. (2005). Testing for weak instruments in linear IV regression. In Andrews D.W.K., Stock J.H. (Eds.), Identification and Inference for Econometric Models: Essays in Honor of Thomas Rothenberg (pp. 80-108). New York: Cambridge University Press. 
Swartz L.H.G., Noell J.W., Schroeder S.W., Ary D.V. (2006). A randomised control study of a fully automated internet based smoking cessation programme. Tobacco Control, 15(1), 7-12.

Tavares A.I. (2020). Self-assessed health among older people in Europe and internet use. International journal of medical informatics, 141, 104240. Advance online publication. DOI: https://doi.org/10.1016/j.ijmedinf.2020.104240 (data downloaded on 10.08.20).

Thun M., Peto R., Boreham J., Lopez A. (2012). Stages of the cigarette epidemic on entering its second century. Tobacco Control, 21(2), 96-101.

Vishnevskiy V.M., Lyakhov A.I., Portnoy S.L., SHakhnovich I.L. (2005). SHirokopolosnyye besprovodnyye seti peredachi informatsii [Broadband communication networks]. Moscow: Tekhnosfera. (In Russ.)

Zaigrayev G.G. (2009). Alcoholism and drunkenness in Russia: ways to come out of the crisis situation. Sociological Research, 8, 74-84. (In Russ.)

ZHerebin V., Alekseyeva O., Vershinskaya O. (2017). Socio-psychological features of Internet users. Population, 1(75), 116-124. (In Russ.) 